\title{
Multiphase Flow and Boiling Heat Transfer Modelling of Nanofluids in a Metal Foam Embedded in Horizontal Tubes
}

\author{
Hayder I. Mohammed ${ }^{1 *}$,Pouyan Talebizadeh Sardari², Donald Giddings ${ }^{2}$ \\ (1) Department of Physics, Collage of Education, University of Garmian, Kurdistan, Iraq \\ (2) Fluids and Thermal Engineering Research Group, Faculty of Engineering, The University of Nottingham, \\ University Park, Nottingham NG7 2RD, UK. \\ * Corresponding author (Hayder I. Mohammed). \\ E-mail addresses: hayder.i.mohammad@garmian.edu.krd, haidarnuceng@gmail.com.
}

\begin{abstract}
The aim of this numerical study is to evaluate the boiling process of nanofluid in horizontal tubes in the presence of a metal foam as a porous medium and represent the experimental work of Zhao et al. in a numerical aspect with a different range of dependent variables. High conductive metal foams are employed to increase the rate of heat transfer and enhance the boiling performance in the domain. The two-phase mixture model is used to simulate the characteristics of nanofluid and solve the governing equations in the two-phase flow and boiling heat transfer problem. $\mathrm{R} 134 \mathrm{a}$ and $\mathrm{ZnO}$ are considered as the base-fluid and nanoparticles, respectively. The characteristics of the metal foam including the porosity and pore density as well as operating conditions including the fluid flow including the velocity, induced heat flux and concentration of nanoparticles on the pressure drop, vapour quality and heat transfer coefficient are examined. The results show the positive effect of the metal foam on the vapour production and overall heat transfer coefficient of the nanofluid in the pipe outlet; however, due to the flow resistance as a result of porous medium addition, a higher pressure drop is achieved. For the heat flux of $19 \mathrm{~kW} / \mathrm{m}^{2}$ and inlet velocity of $0.05 \mathrm{~m} / \mathrm{s}$, by using a metal foam with the porosity of $70 \%$ and pore density of $20 \mathrm{PPI}$, the vapour quality, heat transfer coefficient and pressure drop enhances by $7.1 \%, 9.4 \%$ and $82.7 \%$, respectively, compared with the case of without metal foam. However, by using the porosity of $90 \%$, the vapour quality, heat transfer coefficient and pressure drop enhances by $1.6 \%, 3.5 \%$, and $7.0 \%$, respectively. Consequently, according to the developed results in this paper, a system with a moderate porosity and high pore density is recommended which is finally determined based on the required vapour production and allowed pressure drop.
\end{abstract}

Keywords: Boiling heat transfer, Nano-fluid, Two-phase flow, Mixture model, Porous media, Metal foam, Vapour production. 


\begin{tabular}{|c|c|c|c|}
\hline \multicolumn{4}{|c|}{ Nomenclature } \\
\hline$t$ & Time (s) & \multicolumn{2}{|c|}{ Greek letters } \\
\hline$d_{p}$ & Pore size $(\mathrm{m})$ & $\nabla$ & Vector gradient operator \\
\hline $\mathrm{E}$ & Energy $(\mathrm{J})$ & $\delta$ & Mean distance between the centres of two particles \\
\hline$F$ & Body force $(\mathrm{N})$ & $\varepsilon$ & Porosity \\
\hline$g$ & Gravity $\left(\mathrm{m} / \mathrm{s}^{2}\right)$ & $\epsilon$ & Time relaxation factor $(1 / \mathrm{s})$ \\
\hline $\mathrm{H}$ & Enthalpy $(\mathrm{kJ} / \mathrm{kg})$ & $\mu$ & Viscosity (kg/m.s) \\
\hline$k_{s}$ & $\begin{array}{l}\text { Thermal conductivity of the porous medium } \\
(\mathrm{W} / \mathrm{m} . \mathrm{K})\end{array}$ & $\rho$ & Density $\left(\mathrm{kg} / \mathrm{m}^{3}\right)$ \\
\hline$K$ & Permeability & $\varphi$ & Volume fraction of the particles \\
\hline$K_{b}$ & Boltzmann constant & $\omega$ & Pore density \\
\hline$k_{e f f}$ & Effective thermal conductivity (W/m.K) & & \\
\hline$\dot{m}$ & Mass flow rate $(\mathrm{kg} / \mathrm{s})$ & \multicolumn{2}{|c|}{ Subscripts } \\
\hline $\mathrm{n}$ & Current time step & $\mathrm{dr}$ & Drift velocity \\
\hline $\mathrm{n}+1$ & Next time step & $\mathrm{h}$ & hot \\
\hline$p$ & Pressure $\left(\mathrm{N} / \mathrm{m}^{2}\right)$ & $\mathrm{k}$ & Phase \\
\hline $\mathrm{q}$ & Number of phases & $\mathrm{q}$ & Secondary phase \\
\hline$S$ & Source term & 1 & Liquid \\
\hline$T$ & Temperature $(\mathrm{K})$ & lv & Phase change from liquid to vapour \\
\hline$U_{f}$ & Volume flux of face $\left(\mathrm{m}^{3} / \mathrm{s}\right)$ & $\mathrm{m}$ & mixture \\
\hline$v$ & Velocity $(\mathrm{m} / \mathrm{s})$ & sat & Saturated \\
\hline $\mathrm{V}$ & Volume of cell $\left(\mathrm{m}^{3}\right)$ & $\mathrm{t}$ & Turbulent \\
\hline $\mathrm{x}$ & Length (m) & $\mathrm{v}$ & Vapour \\
\hline
\end{tabular}

\section{Introduction}

The boiling process and the mechanism of the two-phase flow in porous medium occur in different systems, such as geothermal reservoirs, micro-channels and nuclear reactors. Heat transfer via the boiling process and convection phenomenon occurs at the same time and studying their interactions are necessary with practical interest.

In recent decades, boiling process and convection heat transfer in a porous medium have been getting great attention. Whereas, most of the previous works related to the single and two-phase convection processes which are possibly the more dominant method of heat transfer in geothermal systems. Studies on the boiling process and heat transfer phenomena in porous media have been generally experimental [1-8], and numerical [9-16] studies. The use of the porous medium in different applications to enhance the heat transfer rate and modify the heat transfer characteristics has been studied widely such as heat storage applications and heat exchangers [17-31]. The multi-phase flow and boiling process in channels packed with a 
sintered copper bi-dispersed porous medium was experimentally studied by Chen et al. [32]. They observed that the porous material influences the multi-phase heat sink, particularly, for a bi-dispersed porous medium which has a lower flow resistance than that for the mono-dispersed porous materials (both have the same pore size in microscale). Irwansyah and Putra [6] studied a phenomenon of nanofluid pool boiling in a vertical container filled with four different porous media (sintered copper $300 \mu \mathrm{m}$ and $400 \mu \mathrm{m}$, copper screen mesh and stainless steel screen mesh) with different concentrations of aluminium oxide $\left(\mathrm{Al}_{2} \mathrm{O}_{3}\right)$ nanoparticles in water. They indicated that the performance of the heat transfer using sintered copper $400 \mu \mathrm{m}$ is higher than those used in the other porous materials. However, they observed that changing the loading of the nanoparticles has an insignificant effect on the thermal performance. The heat transfer coefficient using copper (porosities $60 \%$ and $80 \%$ ) with homogeneous and hybrid structures in active cooling was studied by Zhu and Zhao [7]. They detected that the heat transfer coefficient inversely proportional with the porosity and parabolically proportional with the water flow rate. Gourbil et al. [33] experimentally studied the effect of the void fraction on the critical heat flux $(\mathrm{CHF})$ for the boiling process in a porous medium. They confirmed that the (CHF) on a specific heating element declines as the heat flux to the porous medium increases. They found also that the void fraction increases with increasing the heating power. Hu et al. [34] experimentally studied on the pressure drop in the refrigerant/oil boiling heat transfer application in a filled metal foam tube with different diameters. They showed that a higher pressure drop for a higher pore density which is more effective in lower tube diameters. Weise et al. [35] studied on pressure drop modelling of flow boiling in an open-cell metal foam as an effective method for heat transfer enhancement. They combined the two-phase pressure drop model for the flow boiling in a tube and one phase pressure drop for the flow inside the porous medium and compared the validity of the model with available experimental data.

Numerically, Ramesh and Torrance [36] investigated the boiling process and naturalconvection heat transfer in a horizontal tube filled with a porous medium at low and high Rayleigh number ( $\mathrm{Ra}$ ). They found that at high Rayleigh numbers, a steady convection heat transfer occurs in a symmetric perturbations trigger, however, an oscillatory heat transfer happens when an asymmetric domain is used. Nazari and Toghraie [15] numerically studied heat transfer and nanofluid ( $\mathrm{CuO}$ based water) flow behaviour in a sinusoidal channel filled with a porous medium. Their results show that the Nusselt number increases with increasing the concentration of the nanoparticle, and they found also that the presence of the porous medium leads to enhance the heat transfer coefficient. Yeo and No [16] Modelled film boiling within chimney-structured porous media and heat pipes. They found that the chimneys density and the pore size have a considerable effect on the heat transfer performance in the Corrosion Residual Unidentified Deposit (CRUD). The researcher observed that there is an optimal number of chimneys to reach maximum performance. Imke [11] simulated numerically microchannel heat transfer and flow in compact heat exchangers. Their model calculated and analysed outlet temperatures, pressure drops and vapour generation during the boiling process. $\mathrm{Lu}$ et al. [13] studied numerically the thermal analysis of a heat exchanger filled with metal foam. Their results show that the overall heat transfer performance is significantly affected by the pore diameter and porosity of the porous medium and they confirm that the use of porous medium can enhance the heat transfer but at the expense of higher pressure drop. A visual study of phase change heat transfer process in a two-dimensional porous channel was performed by 
Liao and Zhao [9]. They found that increasing the heat flux will increase both the frequencies of the bubble growth and the number of isolated bubbles. And when the heat flux is very high, a vapour film was observed below the heated film.

The material of the porous medium has a significant effect on the heat transfer and boiling process. The metal foam porous medium has received much attention in research [1-5, $8,12,13$ ] as it has high thermal conductivity. Zhao et al. [4] experimentally studied the flow boiling heat transfer in horizontal metal foam tubes (20 PPI - 40 PPI). They found that the pressure drop is nonlinearly proportional with the vapour quality and mass flow rates and the pressure drop is significantly affected by the cell size of metal-foam. They found also that the pore size affects the boiling heat transferred as the heat transfer coefficient increases with increasing pore size. The current work is a numerical aspect of the work of Zhao et al. [4] with wider ranges of affected parameter values and using nanofluid ( $\mathrm{ZnO}$ based liquid $\mathrm{R} 134 \mathrm{a}$ ). Zhang et al. [37] studied experimentally on the flow boiling heat transfer to evaluate the performance of porous interconnected microchannel nets for cooling. They show high effects of heat flux on the two-phase heat transfer performance. Samir et al. [38] studied on natural convection boiling heat transfer in a metal foam filled vertical tube for R-134a using the mixture model. They showed that a smaller diameter of the tube results in a higher temperature variation over the entire metal foam tube. Tarawneh [39] studied experimentally the effect of different refrigerants on boiling heat transfer in a porous medium with different porosities. They showed that R422a shows a higher heat transfer performance compared with R22 and R404a helping global warming.

Flow boiling process has more applications (such as boiling in microchannels, steam generation in helical coils and in a nuclear reactor core) than pool boiling [40]. However, studying the behaviour of nanofluid pool boiling [41-51] received more interest from research than nanofluid flow boiling [52-63]. Mohammed et al., numerically [60] and experimentally [61] studied the flow boiling phenomenon of the nano-binary-fluid (acetone / $\mathrm{ZnBr}_{2}$ based on graphene nanoparticles) in a rectangular tube. In both studies, they found that increasing the nanoparticles concentration will enhance the heat transfer coefficient and increase the generated vapour. Also, they found that increasing the surface temperature and the flow rate also increases the heat transfer coefficient. Kim et al. [64] studied subcooled flow boiling using various nanofluid types. They found that the heat transfer coefficient and fluid flow rate of the nanofluid increases during boiling and that the critical heat flux of the flow boiling was increased by $200 \%$ using nanoparticles. Henderson et al. [53] studied the flow boiling heat transfer of nanofluid ( $\mathrm{R} 134 \mathrm{a}-\mathrm{SiO}_{2}$ nanoparticles suspension) in a horizontal tube. They observed that the pressure drop was not affected by the nanoparticles, also they found that using nanoparticles will enhance the heat transfer coefficient to double. A comparison between heat transfer in the horizontal flow and vertical flow studied by Afrand et al. [65] using $\mathrm{TiO}_{2} /$ water and $\mathrm{Al}_{2} \mathrm{O}_{3}$ /water nanofluids found that the vapour quality is different between the cases but the effect of the nanoparticle concentration is almost the same.

From reviewing the previous works, it is obvious that there is no work related to the numerical simulation of nanofluid flow boiling in a copper metal foam (porous medium) under a variation of values of porosity, pore size, flow rate, induced heat flux at the boundary and concentration of $\mathrm{ZnO}$ nanoparticles, which motivate us to run this work by analysing the pressure drop, vapour quality and the heat transfer characteristics of the fluid. The second aim 
of this work is to convert the experimental work of Zhao et al. [4] to numerically analysis and use wider ranges of the affected parameters on the fluid flow pattern and heat transfer performance in the domain.

\section{Mathematical Modelling}

To increase the heat transfer inside the heat transfer fluid (HTF), a porous metal foam is prepared and the fluid is moved through the porous medium [66]. In the numerical modelling, in the presence of a porous medium, a pressure loss is considered due to viscous and inertial losses in the momentum equation [67]. The nanoparticles are modelled as a distinct Eulerian phase to model their presence inside the nanofluid. The two-phase method of the nanoparticles represents a more accurate prediction of the nanofluid characteristics than the single-phase method which uses the effective physical properties of the nanofluid [68, 69]. R134a and $\mathrm{ZnO}$ are considered as the base fluid and nanoparticles respectively.

The following assumptions are made in the present numerical investigation $[18,70]$ :

- To consider the variation of density, Boussinesq approximation is applied due to the small temperature gradient in the domain.

- The porous medium is considered homogeneous and isotropic.

- The thermal equilibrium thermal model is used for the energy equation.

- The nanofluid is assumed to be stable.

The Mixture model is employed in this study due to very strong coupling and phases moving at the same velocity with the assumption of incompressible fluid for the mixture. The governing equations are as follows [71]:

Continuity:

$\nabla \cdot \rho \vec{v}=0$

Momentum:

$\frac{1}{\varepsilon} \nabla \cdot(\rho \vec{v} \vec{v})=-\nabla P+\frac{1}{\varepsilon} \nabla \cdot[\mu \nabla \vec{v}]+\varepsilon \rho g+\varepsilon \nabla \cdot\left(\sum_{k=1}^{q} \varphi_{k} \rho_{k} \vec{v}_{d r i f t} \vec{v}\right)+\vec{F}$

Energy:

$\nabla \cdot \sum_{k=1}^{q}\left(\varphi_{k} \vec{v}_{k}\left(\rho_{k} E_{k}+p\right)\right)=\nabla \cdot\left(k_{e f} \nabla T\right)+S_{E}$

where

$$
E_{k}=h_{k}-\frac{P}{\rho_{k}}+\frac{v_{k}^{2}}{2}
$$

$S_{E}$ is a source term of energy. 
The standard k- $\varepsilon$ turbulence model is used for modelling the boiling fluid considering turbulence kinetic energy $(\mathrm{k})$ and dissipation rate $(\varepsilon)$ which is valid only for fully turbulent flows.

The volume fraction expression is used to calculate the phase volume as follows:

$$
\frac{\partial}{\partial t}\left(\varphi_{v} \rho_{v}\right)+\nabla \cdot\left(\varphi_{v} \rho_{v} \vec{v}_{m}\right)=-\nabla \cdot\left(\varphi_{v} \rho_{v} \vec{v}_{\text {drift }} \vec{v}\right)+S_{M}
$$

where the mass source term $S_{M}$ is defined as:

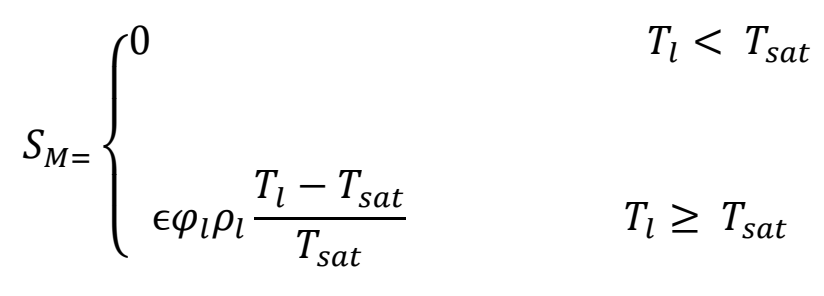

In the energy equation, the source term is defined as:

$$
S_{E}=-\epsilon \varphi_{l} \rho_{l}\left|\frac{T_{l}-T_{s a t}}{T_{s a t}}\right| \Delta h_{f g}
$$

where $h_{f g}$ is the enthalpy of the evaporation, $T_{\text {sat }}=282 \mathrm{~K}$ is the saturation temperature and $\epsilon$ is a time relaxation factor with unit $1 / \mathrm{s}$, which can be calculated as:

$$
\epsilon=\frac{6}{d_{b}} \beta \sqrt{\frac{M}{2 \pi R T_{\text {sat }}}} L\left(\frac{\varphi_{v} \rho_{v}}{\rho_{l}-\rho_{v}}\right)
$$

where $d_{b}$ is bubble diameter, $\beta$ is accommodation coefficient, $M$ is molar mass of R134a, $R$ is gas constant, $L$ is latent heat for R134a, $\varphi_{v}$ is vapour quality. Equations 6 and 7 defined by Lee [72] and validated in different studies $[60,73,74]$.

In order to operate this model, the viscosity of each phase should be accounted. Therefore, the nanoparticles are assumed to be as a cloud. Masoumi et al. [75] developed a formula to calculate the viscosity of the nanoparticle cloud, with respect to the Brownian motion of nanoparticles:

$$
\frac{\mu_{n f}}{\mu_{f}}=1+\frac{\rho_{p} v_{B} d_{p}^{2}}{72 C \delta}
$$

where $v_{\boldsymbol{B}}$ (velocity of Brownian motion), $\delta$ (the mean distance between the centres of two particles) and $\mathrm{C}$ (correction factor) are given as:

$$
v_{B}=\frac{1}{d_{p}} \sqrt[3]{\frac{18 K_{b} T}{\pi \rho_{p} d_{p}}}
$$




$$
\begin{aligned}
& \delta=\sqrt[3]{\frac{\pi d_{p}}{6 \varphi}} \\
& C=\frac{a \Omega+b}{\mu_{f}}
\end{aligned}
$$

where $\mathrm{Kb}$ is the Boltzmann constant $\left(1.38 \times 10^{-23} \mathrm{~m}^{2} \mathrm{~kg} / \mathrm{s}^{2} \mathrm{~K}\right), \mathrm{a}=-4 \times 10^{-5}$ and $\mathrm{b}=7.13 \times 10^{-7}$ and it is found to be valid only when $\Omega<-b / a$.

To calculate the viscosity of the nanofluid in the two phase model, both the viscosities of the nanoparticle cloud and the base fluid combined according to equations 13 and 14 .

$$
\begin{aligned}
& \rho_{m}=\sum_{k=1}^{n} \varphi_{k} \rho_{k} \\
& \mu_{m}=\sum_{k=1}^{n} \varphi_{k} \mu_{k}
\end{aligned}
$$

The volume average of the thermal conductivities of porous matrix material and nanofluid is used in the energy equation to find the effective thermal conductivity of the fluid as $[31,76]$ :

$$
k_{e f}=(1-\varepsilon) k_{s}+\varepsilon k_{f}
$$

where $k_{s}$ and $k_{f}$ are the thermal conductivities of solid (porous material) and fluid, respectively and $\varepsilon$ is the porosity of the matrix.

The last term on the right-hand side of the momentum equation is due to the presence of the porous medium and is calculated as [31]:

$$
\vec{F}=\left(\frac{\mu_{f}}{K}+\frac{\rho_{f} C|v|}{\sqrt{K}}\right) \vec{v}
$$

In the above equation, the first term is the viscous loss term and the second term is the inertial loss term where $K$ is the permeability and $C$ is the inertial coefficient given as [67]:

$$
\begin{aligned}
& K=0.00073 d_{p}^{2}(1-\varepsilon)^{-0.224}\left(\frac{d_{l}}{d_{p}}\right)^{-1.11} \\
& C=0.00212(1-\varepsilon)^{-0.132}\left(\frac{d_{l}}{d_{p}}\right)^{-1.63}
\end{aligned}
$$

where $d_{l}$ is the ligament or cell diameter obtained as:

$$
d_{l}=1.18 d_{p} \sqrt{\frac{1-\varepsilon}{3 \pi}}\left(\frac{1}{1-e^{-(1-\varepsilon) / 0.04}}\right)
$$


and $d_{p}$ is the pore size calculated as:

$$
d_{p}=0.0254(m) / \omega(P P I)
$$

where $\omega$ is the pore density and PPI means pores per inch.

The overall heat transfer coefficient is defined as the ratio of the constant heat flux applied in the pipe wall $\left(q_{w}\right)$ to the average temperature difference between the wall and fluid $(\Delta T)$ given as:

$$
h=\frac{q_{w}}{\Delta T}
$$

The inlet temperature of the fluid flow is constant equal to $281 \mathrm{~K}$ and the outlet temperature is determined by the simulation for different studied cases.

\section{Geometry, Boundary condition and fluid properties}

The studied geometry is a horizontal tube filled with metal-foam shown in Figure 1 with the inner diameter of $2.6 \mathrm{~cm}$ and length of $15 \mathrm{~cm}$. Copper is used as the material of the metal foam due to having a high thermal conductivity. The inlet temperature, pressure and vapour quality of the fluid flow are constant $281 \mathrm{~K}, 3.5 \mathrm{bar}$ and 0.2 , respectively. The outflow boundary condition is chosen for the pipe outlet. Different values of inlet velocity and heat flux applied on the walls are examined.

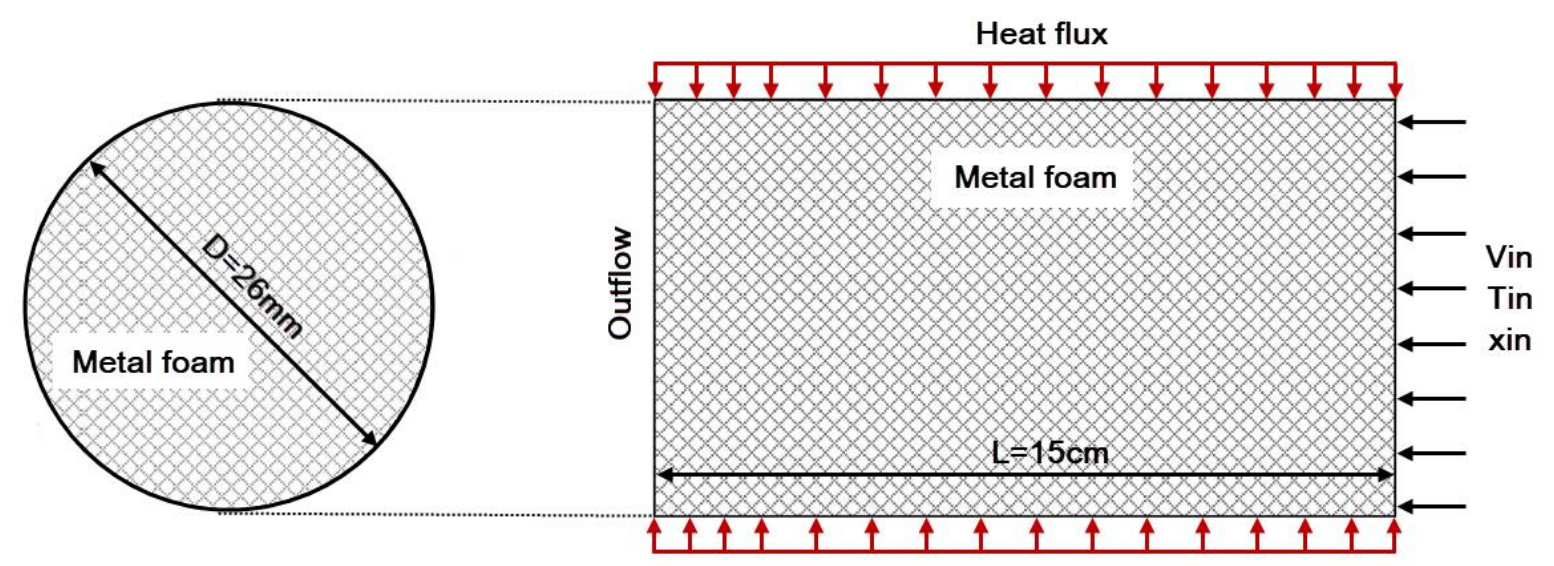

Figure 1. A schematic view of a horizontal tube (in front and side section) filled with a metal foam including the dimensions and boundary conditions

The base fluid and nanoparticles examined in this study are $\mathrm{R} 134 \mathrm{a}$ and $\mathrm{ZnO}$ and Table 1 presents the thermophysical properties of them.

Table 1: The thermophysical properties of the materials used in this study at $\mathrm{P}=3.5$ bar. 


\begin{tabular}{ccccc}
\hline & $\begin{array}{c}\text { Density } \\
\left(\mathrm{kg} / \mathrm{m}^{3}\right)\end{array}$ & $\begin{array}{c}\text { Heat capacity } \\
(\mathrm{kJ} / \mathrm{kg} . \mathrm{K})\end{array}$ & $\begin{array}{c}\text { Thermal conductivity } \\
(\mathrm{W} / \mathrm{m} . \mathrm{K})\end{array}$ & $\begin{array}{c}\text { Viscosity } \\
(\mathrm{kg} / \mathrm{m} . \mathrm{s})\end{array}$ \\
\hline R134a (liquid) & 1280 & 1.267 & 0.1056 & $4.1^{*} 10^{-4}$ \\
R134a (vapour) & 16.7 & 0.835 & 0.014 & $1.2^{*} 10^{-5}$ \\
ZnO & 1576 & 40.3 & 36 & $0.00225_{\text {(cloud) }}$ \\
\hline
\end{tabular}

\section{Numerical procedure}

ANSYS-FLUENT software is used to solve the governing equations discretised with double precision solver using the SIMPLE algorithm with PRESTO scheme for pressure correction equation and QUICK scheme for the momentum and energy equations. The convergence criteria for continuity, momentum and energy equations are set to $10^{-4}, 10^{-6}$ and $10^{-6}$, respectively. A no-slip condition is applied for liquid and vapour phase velocities on the channel surface. Note that due to the symmetric nature of the problem, only half of the geometry is generated and simulated.

For the mesh independency analysis, different meshes consisting entirely of hexahedral control volume are generated with different number of elements. Figure 2 displays a schematic of the created meshed at ANSYS at different cross-sections of the domain. A denser mesh is generated near the walls due to the boundary layer effect (first layer high is $1.25^{*} 10^{-5} \mathrm{~m}$ ).

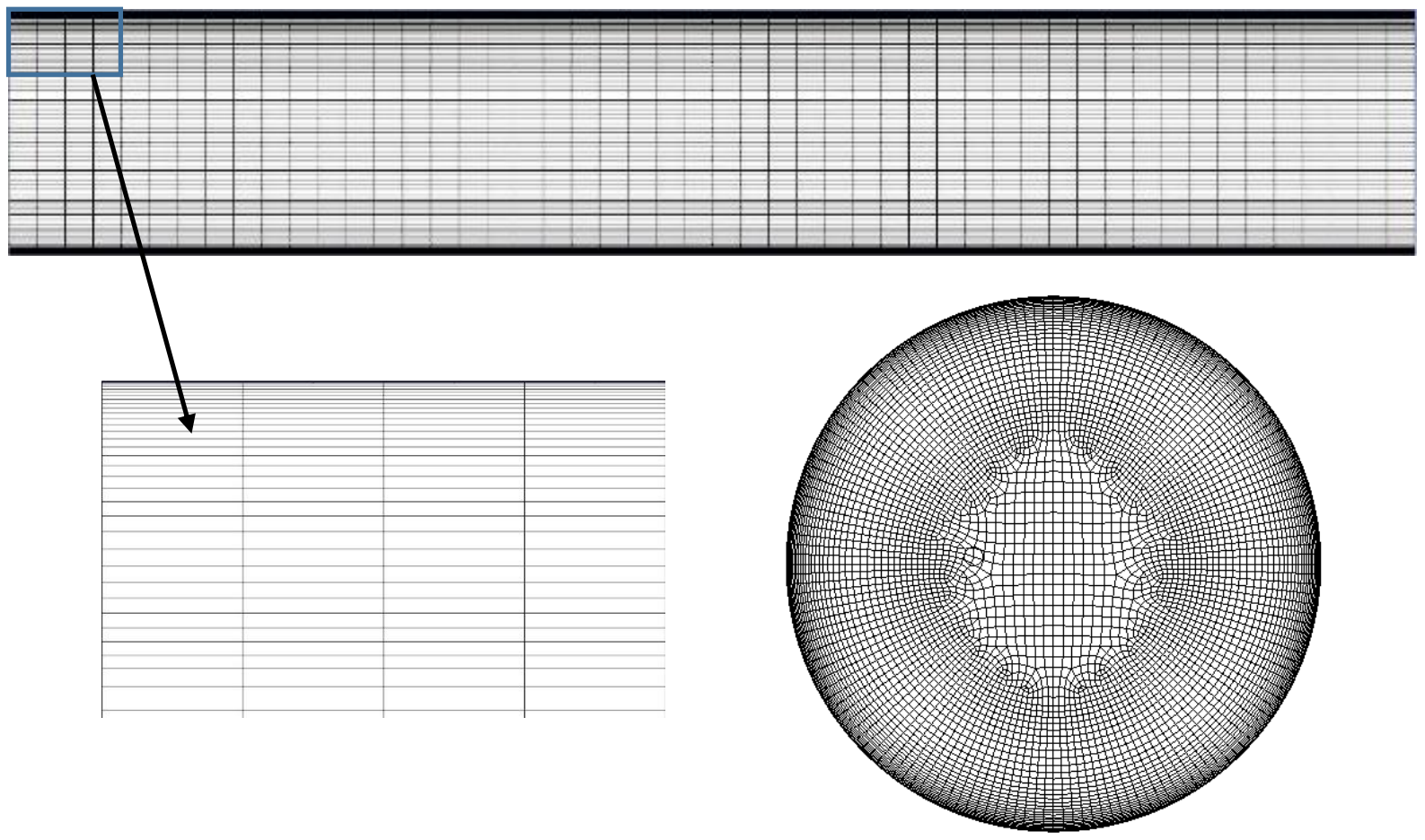

Figure 2. The generated mesh at different cross sections. 
Table 2 presents the effect of element number on the pressure drop, heat transfer coefficient and vapour quality and also represents the required time for each simulation. After employing 321500 elements, the variations in various parameters are very small and therefore according to the time of the simulation, the mesh with the element number of 321500 is chosen for further analysis. The number of elements could be reduced by increasing the porosity and the PPI since the pore dimension increases. In this study, the constant maximum mesh element size (321500) is chosen as the number of elements for the lowest porosity and pore density.

Table 2 The mesh indecency analysis through showing the effect of element number on the pressure drop, heat transfer coefficient and vapour quality.

\begin{tabular}{ccccccc}
\hline $\begin{array}{c}\text { Number of } \\
\text { elements }\end{array}$ & 250106 & 295675 & 321500 & 343775 & 385030 & 410500 \\
\hline $\mathrm{h}\left(\mathrm{w} / \mathrm{m}^{2} \cdot \mathrm{K}\right)$ & 3865 & 3878 & 3890 & 3893 & 3898 & 3894 \\
$\mathrm{dx}$ & 0.272 & 0.281 & 0.291 & 0.293 & 0.295 & 0.294 \\
$\mathrm{dp} / \mathrm{l}(\mathrm{Pa} / \mathrm{m})$ & 54533 & 56200 & 57023 & 57508 & 57855 & 57122 \\
time of & 54 & 78 & 112 & 154 & 193 & 238 \\
simulation (min) & & & & & & \\
\hline
\end{tabular}

\section{Results and discussion}

Firstly, the FLUENT code is verified, then the effect of different parameters on the pressure drop, heat transfer coefficient and vapour quality are presented. The effective parameters are the porosity $(0.5,0.6,0.7,0.8,0.9 \& 1)$ and pore density in PPI $(20,30,40,50 \& 60)$ of metal foam, the volume fraction $(0,0.005,0.01,0.015,0.03 \& 0.05)$ of nanoparticles, the heat flux $\left(19,25,30,35 \& 40 \mathrm{~kW} / \mathrm{m}^{2}\right)$ and the inlet velocity $(0.05,0.1,0.15,0.2,0.25 \& 0.3 \mathrm{~m} / \mathrm{s})$.

\subsection{Validation}

To validate the model, the results are first compared with the results of Zhao et al. [77] for flow and heat transfer of a boiling fluid in a horizontal tube filled with a porous metal structure. Zhao et al. [77] studied experimentally the effect of porous characteristics including the porosity and pore density on the boiling process of R134a fluid in a horizontal metal-foam filled tube according to the pressure drop, heat transfer coefficient and vapour fraction. Figures 3 illustrates the variation of pressure drop in terms of mass flux for different pore density of the metal foam. The pressure drop of present work is obviously larger than that in the literature because of the difference between the real object and its assumed model on both the physical and mathematical sides. Figure 4 displays the variation of heat transfer coefficient for different inlet velocities as a function of vapour quality for the porosity of $90 \%$ and vapour quality of 0.3 at the inlet. The heat transfer is deteriorated with reducing the inlet velocity because the software calculates the heat transfer via Reynold number which proportional with the inlet 
velocity. As shown, the results of the present study are in good agreement with the experimental results of Zhao et al. [77] for different effective parameters.

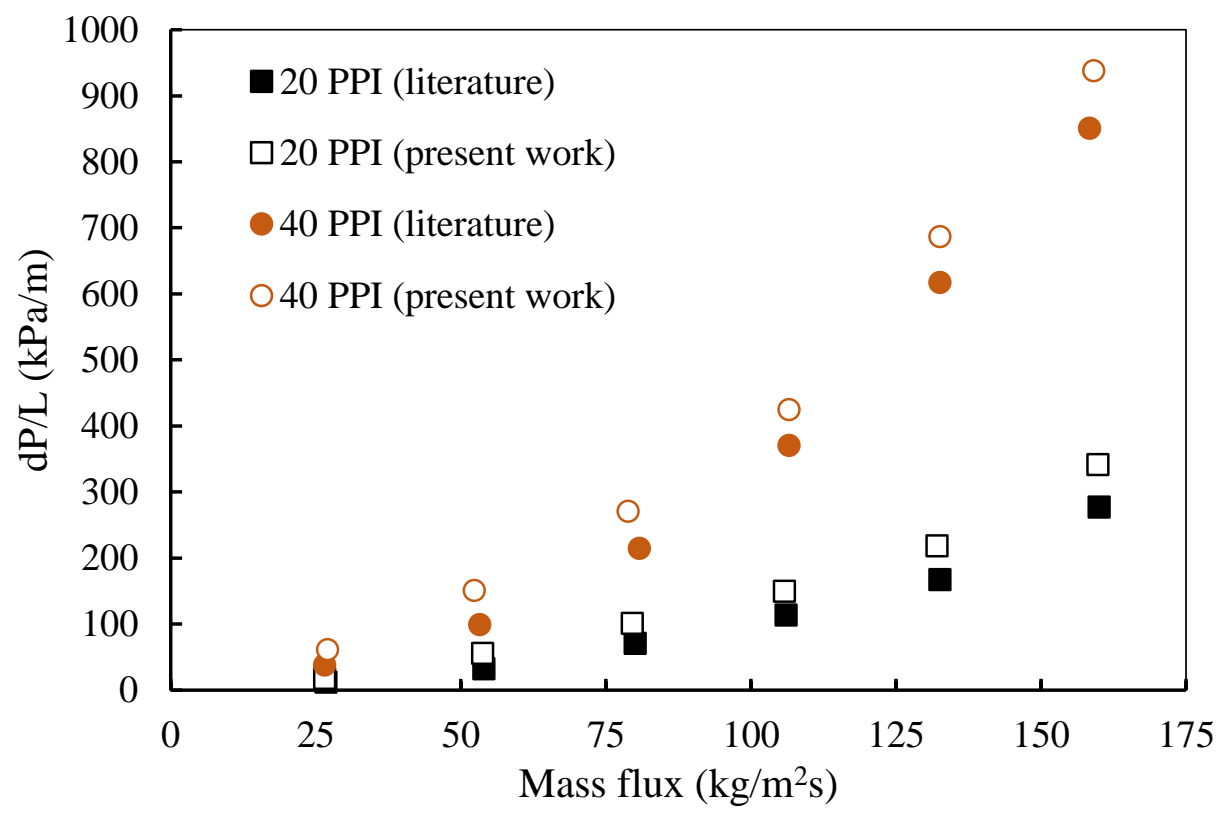

Figure 3. The variation of pressure drop as a function of inlet mass flux for different pore density for the porosity of $90 \%$ and inlet vapour quality of 0.3 .

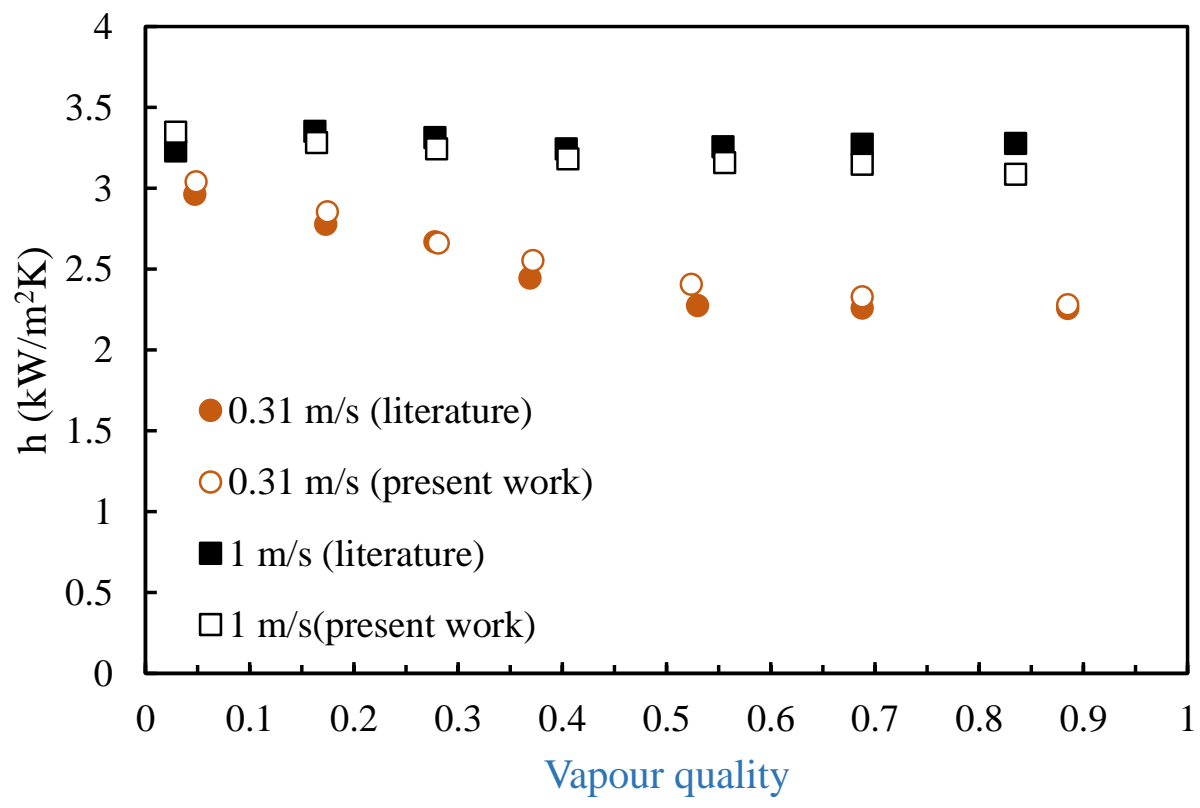

Figure 4. Heat transfer coefficient as a function of vapour quality for different inlet velocity for the porosity of $90 \%$ and pore density is 20 PPI.

\subsection{Study of velocity and temperature distribution}

To reach a better understanding of the behaviour of flow boiling, the results are first presented based on velocity and temperature distributions through different contour plots. Figure 5 
illustrates the contour plot of velocity distribution at $\mathrm{x}$-plane midsection (Figure 5-a) and different cross-sections of yz-plane (Figure 5-b) for the porosity of 0.7 and inlet velocity of $0.05 \mathrm{~m} / \mathrm{s}$. As shown in Figure 5-a, at the beginning length of the tube from the inlet (left side of the tube), the generated velocity profile is regularly similar to a pipe flow since the boiling process is not started due to lack of sufficient heat from the boundary and as a result lower temperature of the fluid than the boiling temperature. After $x=120 \mathrm{~mm}$ (Figure 5-b), the velocity profile starts changing from the parabolic shape because of generating more vapour in the domain. The effect of the boiling process in the domain can be seen perfectly in Figure 5$b$ at the pipe outlet $(x=150)$. High velocity near the wall can be seen due to the vapour generation in this area where a higher amount of heat is gained by the liquid.
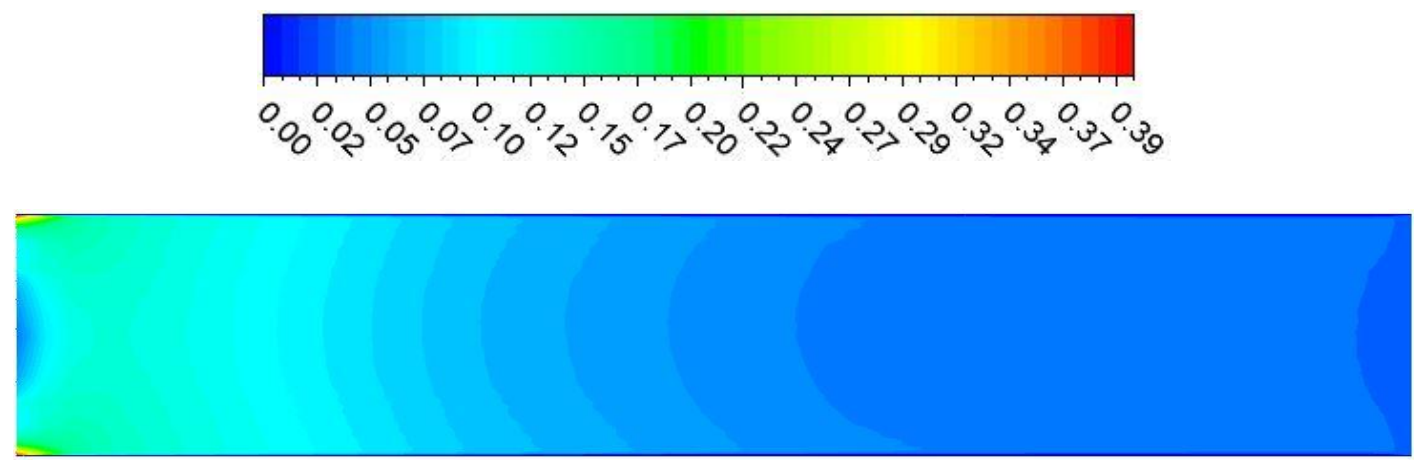

a)
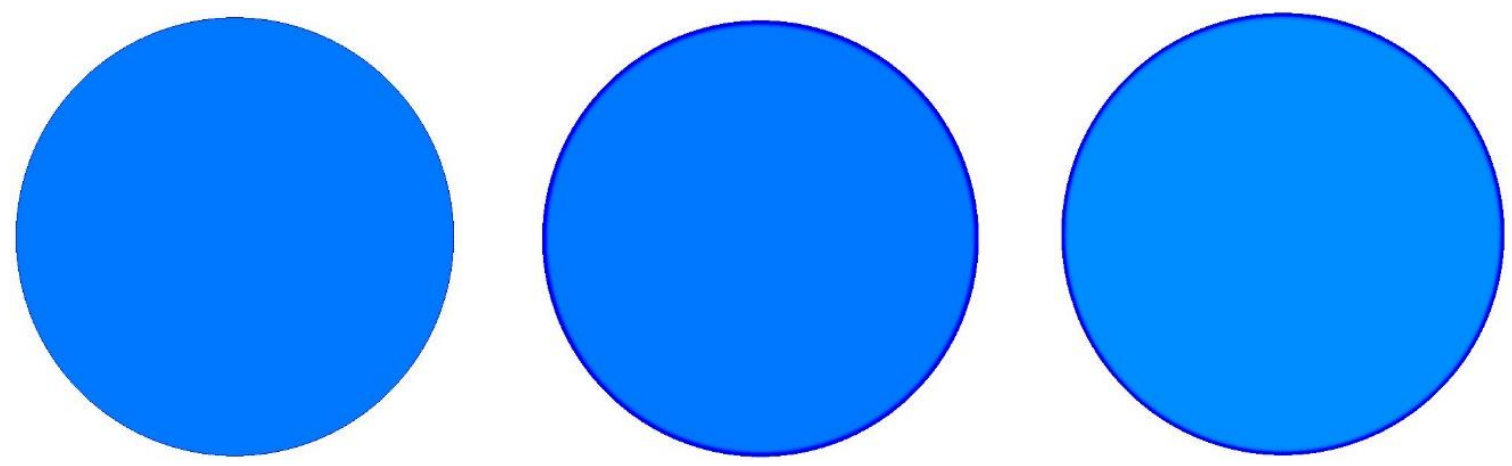

$\mathrm{X}=0 \mathrm{~mm}$

$\mathrm{x}=30 \mathrm{~mm}$

$\mathrm{x}=60 \mathrm{~mm}$

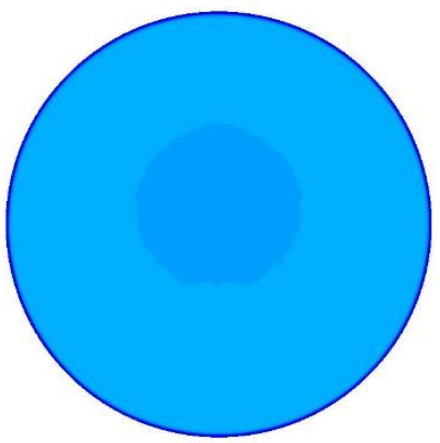

$\mathrm{x}=90 \mathrm{~mm}$

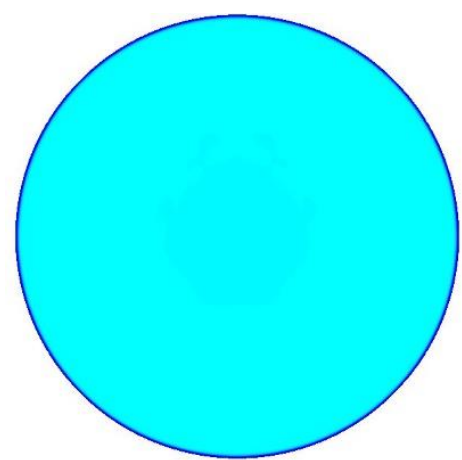

$\mathrm{x}=120 \mathrm{~mm}$

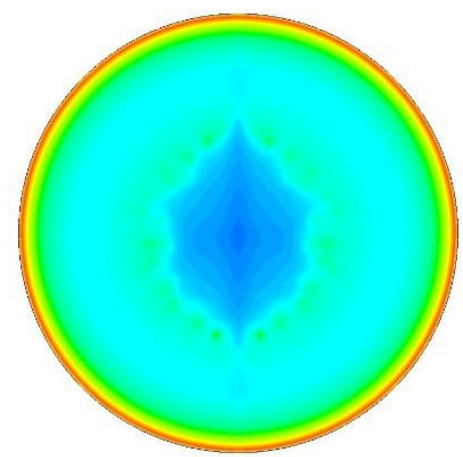

$\mathrm{x}=150 \mathrm{~mm}$ 
b)

Figure 5. The contours of velocity distribution at a) x-plane midsection (symmetric section), and b) different cross-sections in yz-plane.

Figure 6 illustrates the contour plot of temperature distribution at x-plane midsection (Figure 6-a) and different cross-sections of yz-plane (Figure 6-b) for the porosity of 0.7 and inlet velocity of $0.05 \mathrm{~m} / \mathrm{s}$. When the fluid is close to the pipe outlet, the temperature of the fluid increases by gaining more heat from the wall. The average temperature difference between the outlet and inlet of the pipe is $27{ }^{\circ} \mathrm{C}$. When the temperature reaches as high as the boiling temperature of nanofluid $(282 \mathrm{~K})$, the boiling process starts which happens after the entrance of the channel according to Figure 5.
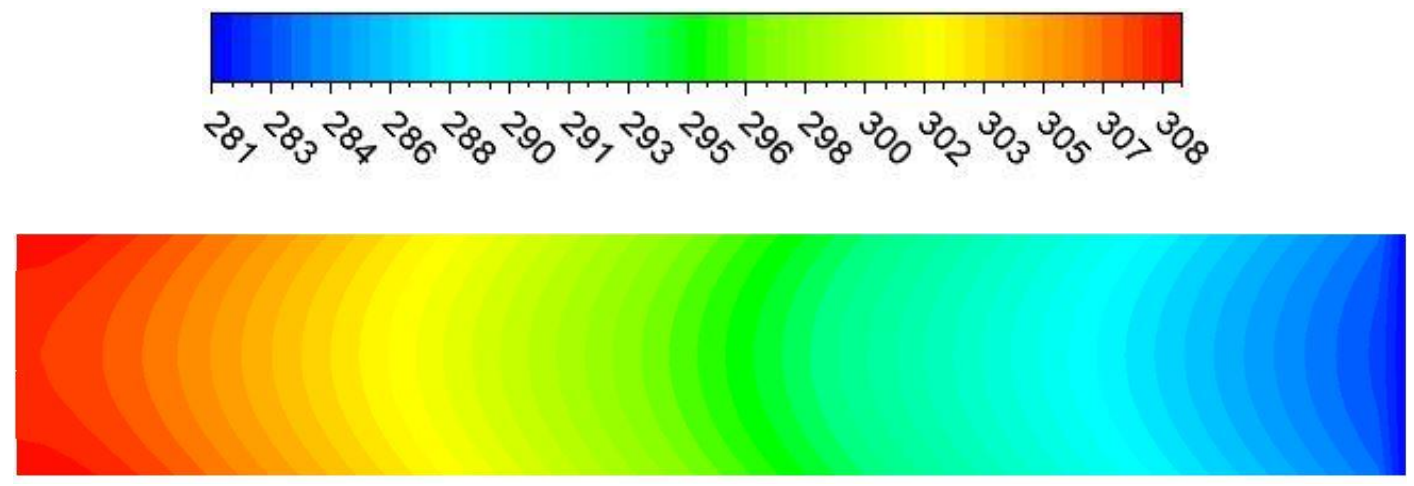

a)

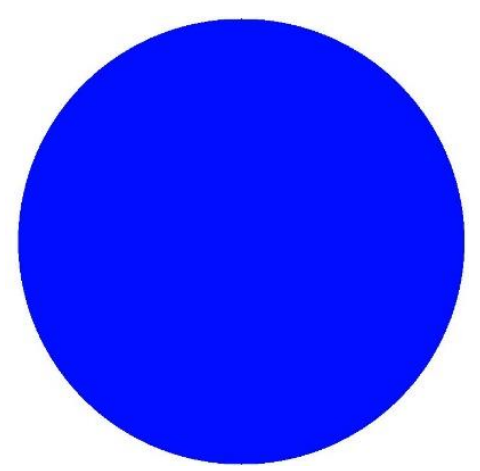

$\mathrm{x}=0 \mathrm{~mm}$

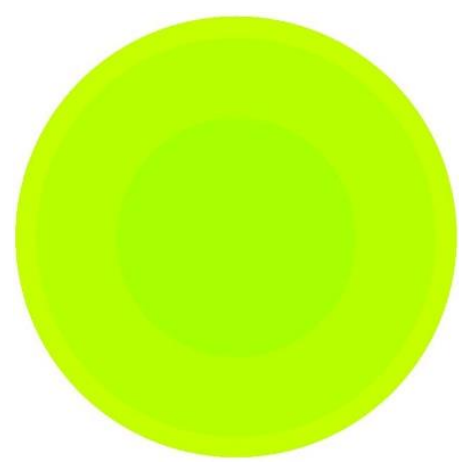

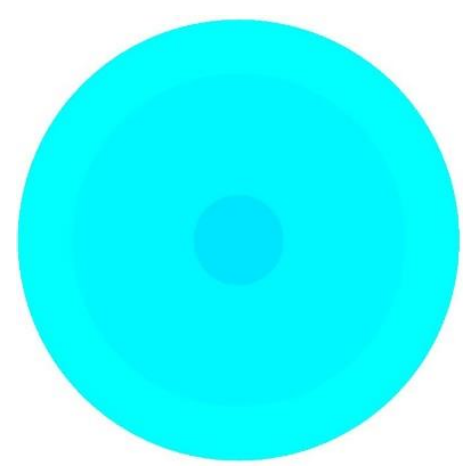

$\mathrm{x}=30 \mathrm{~mm}$

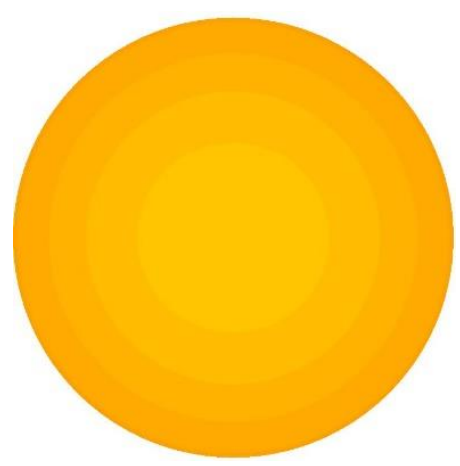

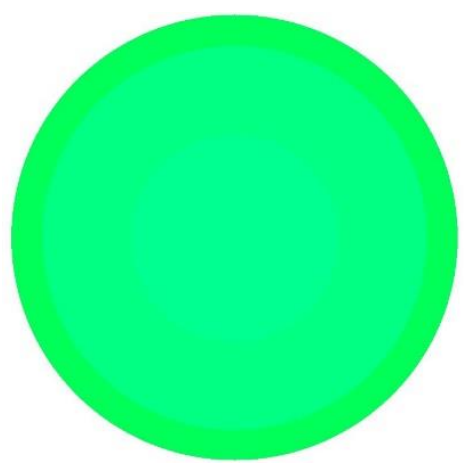

$\mathrm{x}=60 \mathrm{~mm}$

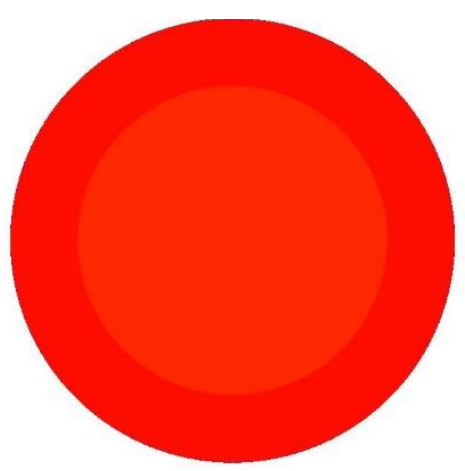


b)

Figure 6. The contours of temperature distribution at a) x-plane midsection (symmetric section), and b) different cross-sections in yz-plane.

The aim of adding high thermal conductivity metal foams such as copper foam in the boiling heat transfer process is enhancing the rate of heat transfer due to the higher thermal conductivity of the metal foam than the base fluid. On the other hand, flow resistance is made in the fluid path which makes a higher pressure drop in the domain. However, using a porous medium instead of solid structures reduces the effect of pressure drop, especially for higher porosity of the foams. Therefore, the effects of metal foam addition on the rate of heat transfer and pressure drop depend on the characteristics of the metal foam including the porosity and pore density as well as operating conditions of the problem. In the boiling process of nanofluid, the volume fraction of nanoparticles is also effective on the rate of heat transfer and pressure drop. In the following, the effect of different parameters on the pressure drop, convective heat transfer coefficient and vapour fraction of the boiling fluid are studied.

\subsection{Study of the pressure drop}

Figure 7 shows the variation of pressure drop per unit length as a function of porosity for different heat fluxes applied on the walls for $\varphi=0.01, \omega=20 \mathrm{ppi}$ and $V_{i n}=0.05 \mathrm{~m} / \mathrm{s}$. Note that the porosity of 1 means the geometry without the metal foam. As expected, increasing the porosity of the metal foam results in a lower pressure drop due to a lower presence of solid porous structure and as a results lower resistance in the flow direction. Another reason for this phenomenon is with increasing the porosity, more vapour in the channel increases the resistance to flow thereby increasing the total pressure drop across the channel. Furthermore, for a higher wall heat flux, the pressure drop enhances. By increasing the input heat flux applied on the walls, the temperature of the fluid increases more rapidly. Therefore, more mass of the liquid is boiled to vapour which causes a higher pressure drop in the domain due to the high volume flow rate. 


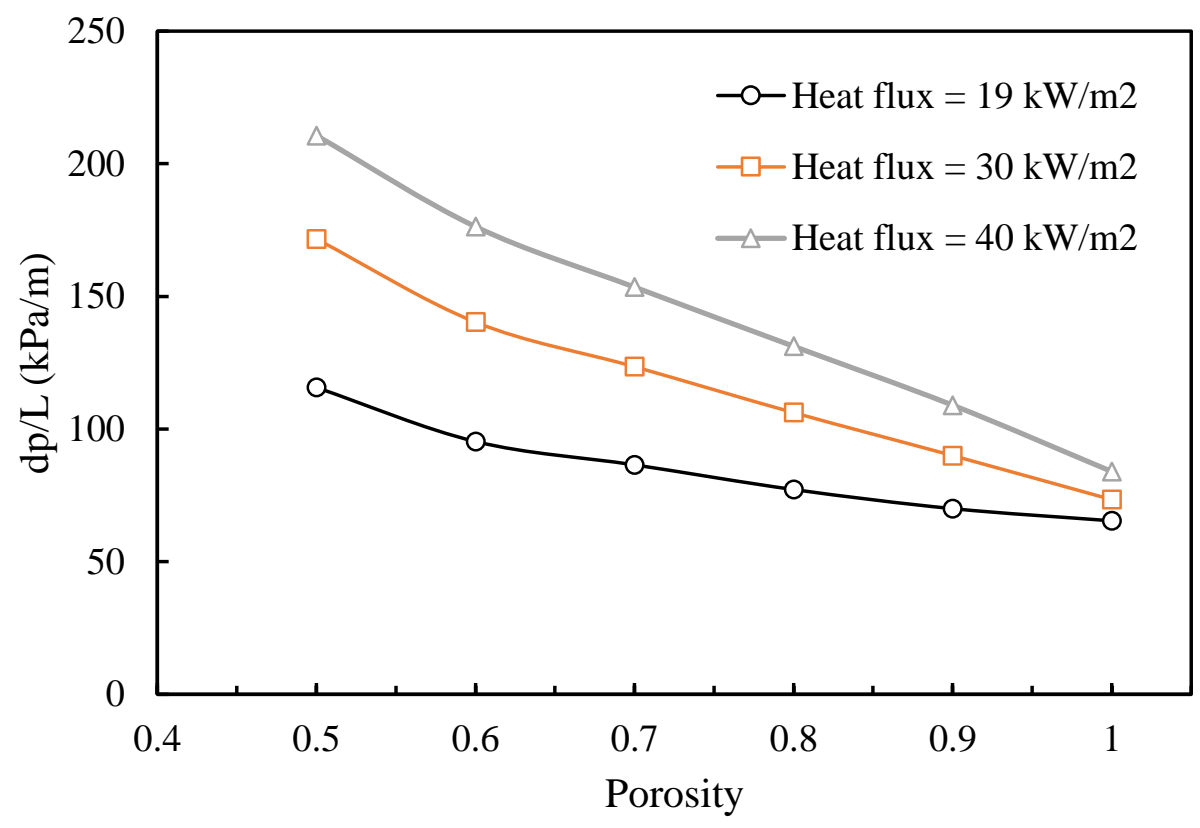

Figure 7. The variation of pressure drop per unit length in terms of the porosity for different values of input heat fluxes.

Figure 8 illustrates the variation of pressure drop per unit length $\left(\frac{d P}{L}\right)$ as a function of flow velocity for different pore density for $\varphi=0.01, \varepsilon=0.9$ and $\dot{Q_{w}}=19 \mathrm{~kW} / \mathrm{m}^{2}$. The flow resistance in a channel filled with porous medium generates within three effects: channel surface drag resistance, Darcy viscous resistance, and resistance caused by porous structures (last two effects appear with the presence of porous medium). With increasing the velocity, the drag resistance increases which causes an increase in the pressure drop. Increasing the vapour quality, caused by increasing the void fraction when the flow rate increases, also leads to increase in the pressure drop. Furthermore, for a higher pore density and as a result, the smaller size of the pores, the pressure drop increases expectedly due to the presence of a higher number of pores in the pipe which results in higher flow resistance in the flow direction of the pipe. 


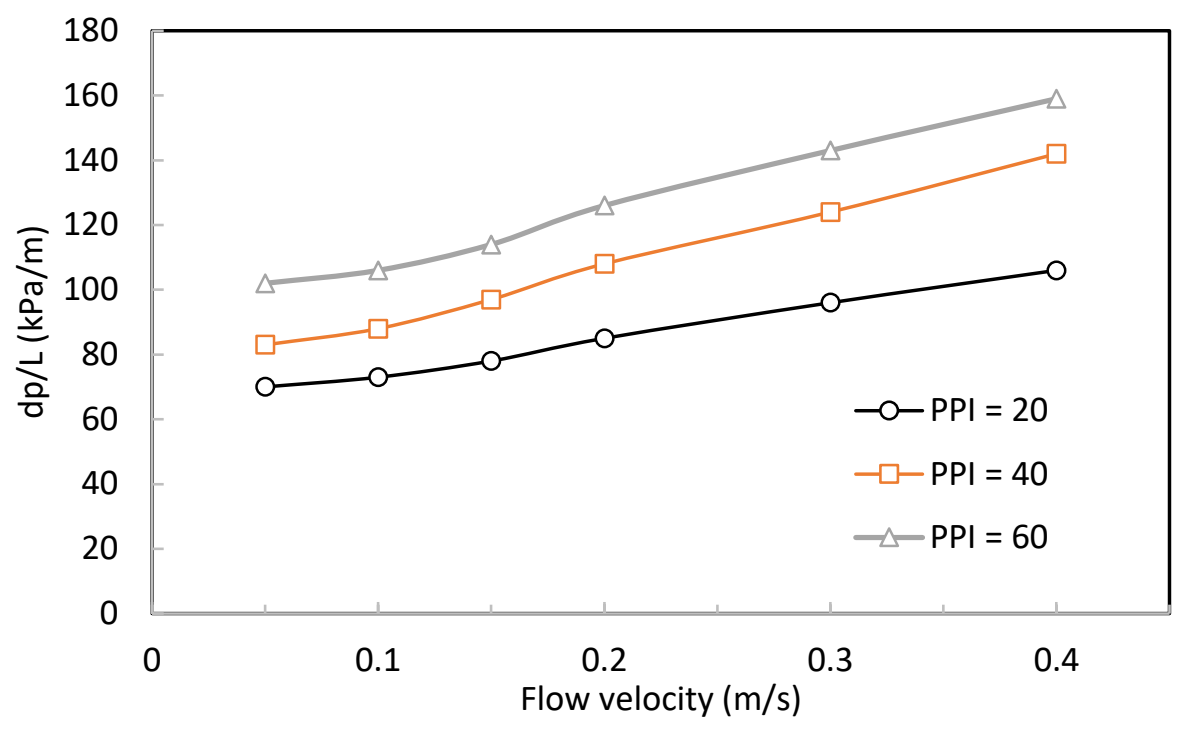

Figure 8. The variation of pressure drop per unit length in terms of the flow velocity for different values of pore density of the metal foam.

Figure 9 shows the variation of pressure drop per unit length as a function of volume fraction of nanoparticles for different porosity of the metal foam for $\dot{Q}_{w}=19 \mathrm{~kW} / \mathrm{m}^{2}, \omega=20$ and $V_{\text {in }}=0.05 \mathrm{~m} / \mathrm{s}$. By increasing the concentration of nanoparticles, the pressure drop reduces and the figure clearly shows that the pressure drop also reduces with increasing the porosity.

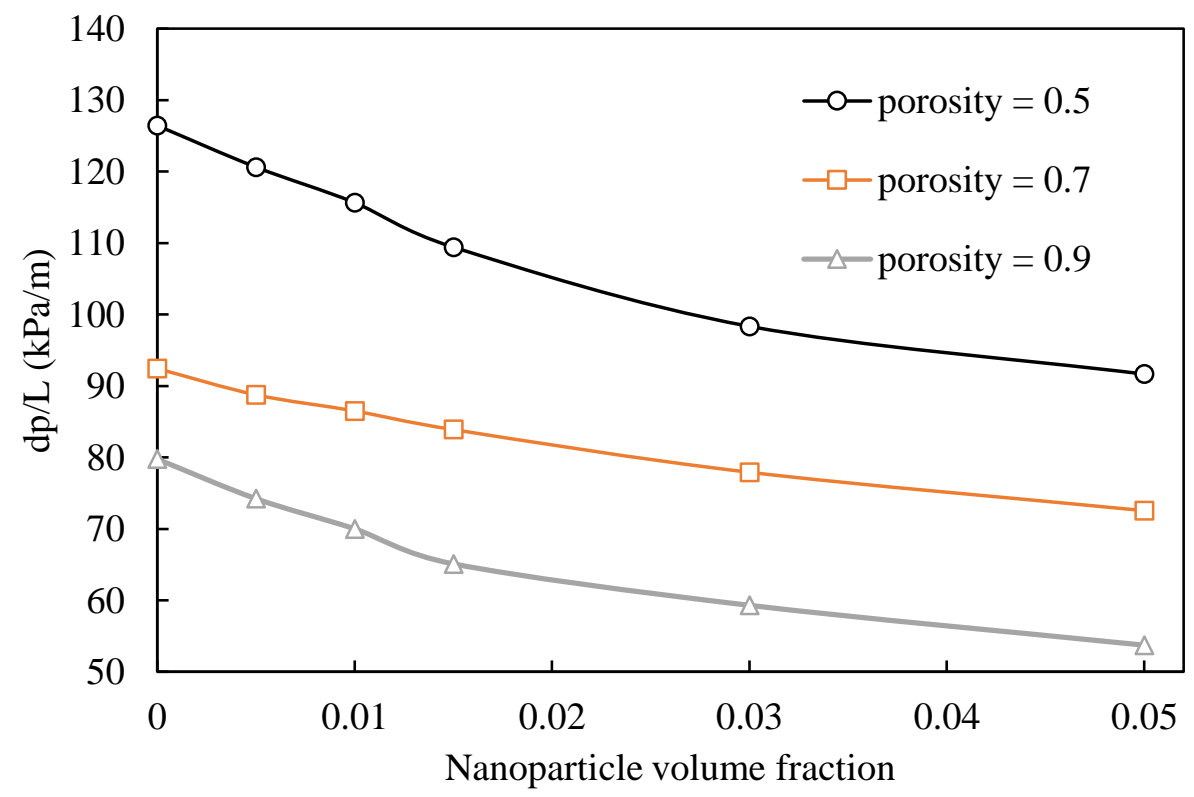

Figure 9. The variation of pressure drop per unit length in terms of nanoparticle volume fraction for different metal foam porosities.

\subsection{Study of vapour quality}


Figure 10 shows the variation of vapour fraction as a function of porosity for different heat fluxes applied on the walls for $\varphi=0.01, \omega=20$ and $V_{\text {in }}=0.05 \mathrm{~m} / \mathrm{s}$. The vapour fraction reduces by increasing the porosity of metal foam. For a lower porosity of metal foam and as a result higher presence of a high conductive solid porous medium structure, the rate of heat transfer increases in the domain and therefore the temperature rises faster. Therefore, a lower amount of vapour is generated using a higher porosity of metal foam. Furthermore, for a higher wall heat flux, the vapour fraction enhances expectedly due to a higher temperature of the fluid as a result of higher input heat.

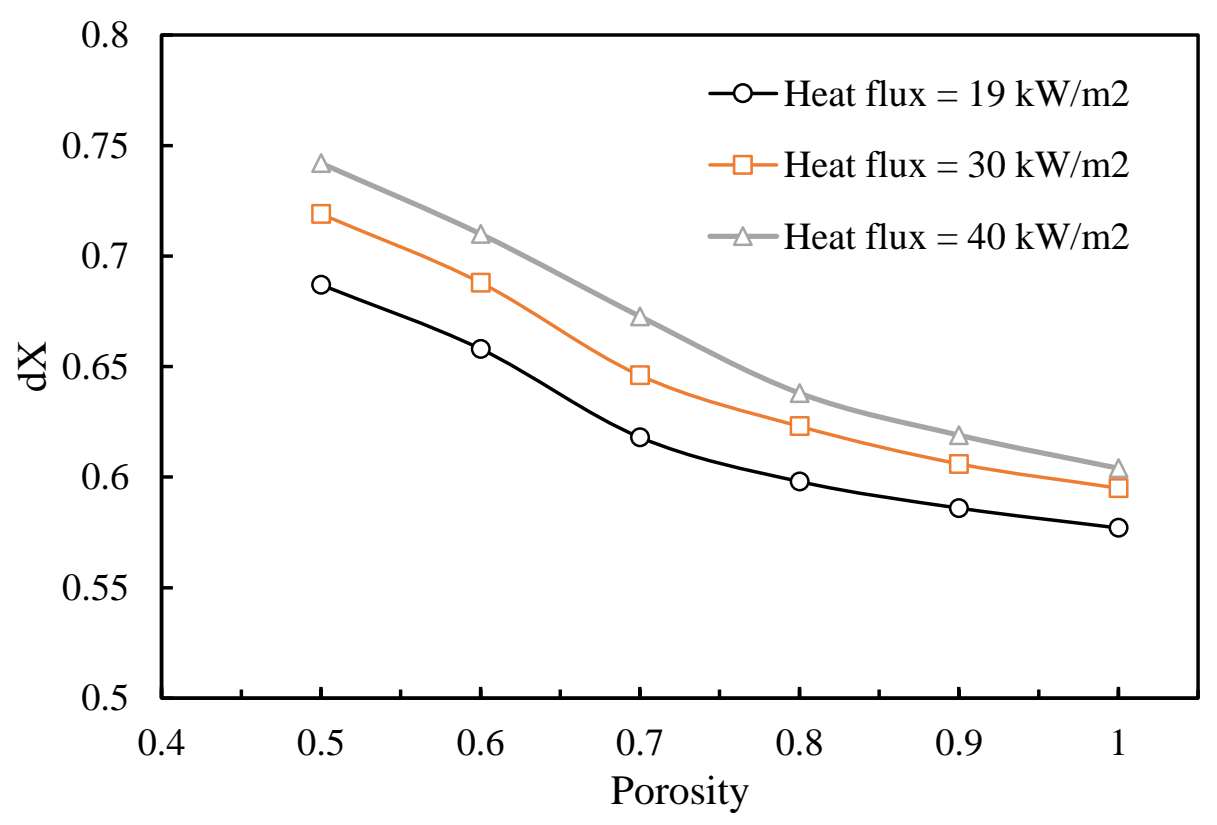

Figure 10. The variation of vapour quality in terms of the porosity for different values of input heat fluxes (vapour quality is relative to the open part of the channel, not all the volume, which contain the solid state of the foam).

Figure 11 illustrated the variation of vapour fraction as a function of flow velocity for different pore density for $\varphi=0.01, \varepsilon=0.9$ and $\dot{Q_{w}}=19 \mathrm{~kW} / \mathrm{m}^{2}$. The vapour fraction reduces for higher inlet velocity of the fluid flow. The reason is that for a higher inlet velocity of the flow, the residence time of the fluid in the pipe reduces results in a lower heat gain by the fluid. Therefore, a lower amount of vapour fraction is achieved by increasing the velocity of the fluid flow. Furthermore, for a higher pore density and as a result smaller size of the pores, the vapour fraction increases due to a higher rate of heat transfer in the domain. However, as shown, the effect of pore size reduces by increasing the velocity of the fluid flow. 


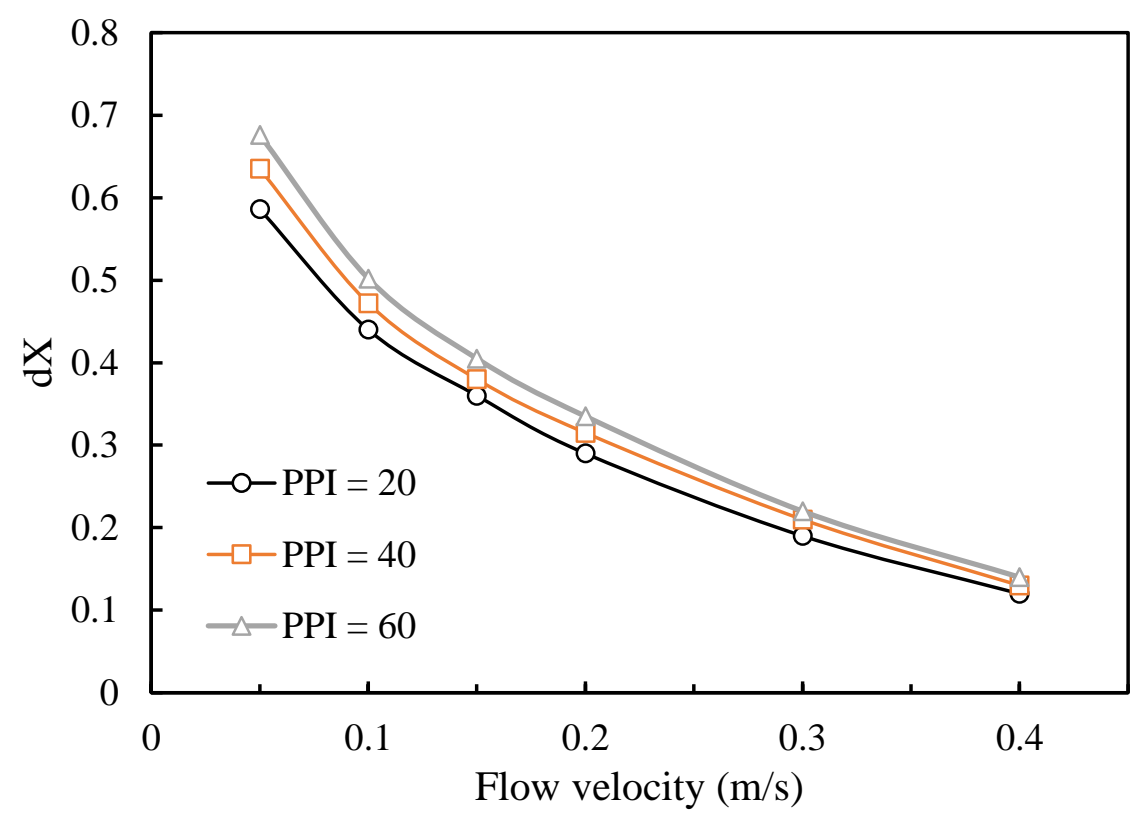

Figure 11. The variation of vapour fraction in terms of the flow velocity for different values of pore density of the metal foam.

Figure 12 shows the variation of vapour fraction as a function of volume fraction of nanoparticles for different porosity of the metal foam for $\dot{Q}_{w}=19 \mathrm{~kW} / \mathrm{m}^{2}, \omega=20$ and $V_{\text {in }}=$ $0.05 \mathrm{~m} / \mathrm{s}$. Increasing the concentration of nanoparticles will enhance the heat transfer rate of the system due to the high thermal conductivity of the nanoparticles. This leads the fluid to achieve the saturation temperature faster, and then more vapour generated.

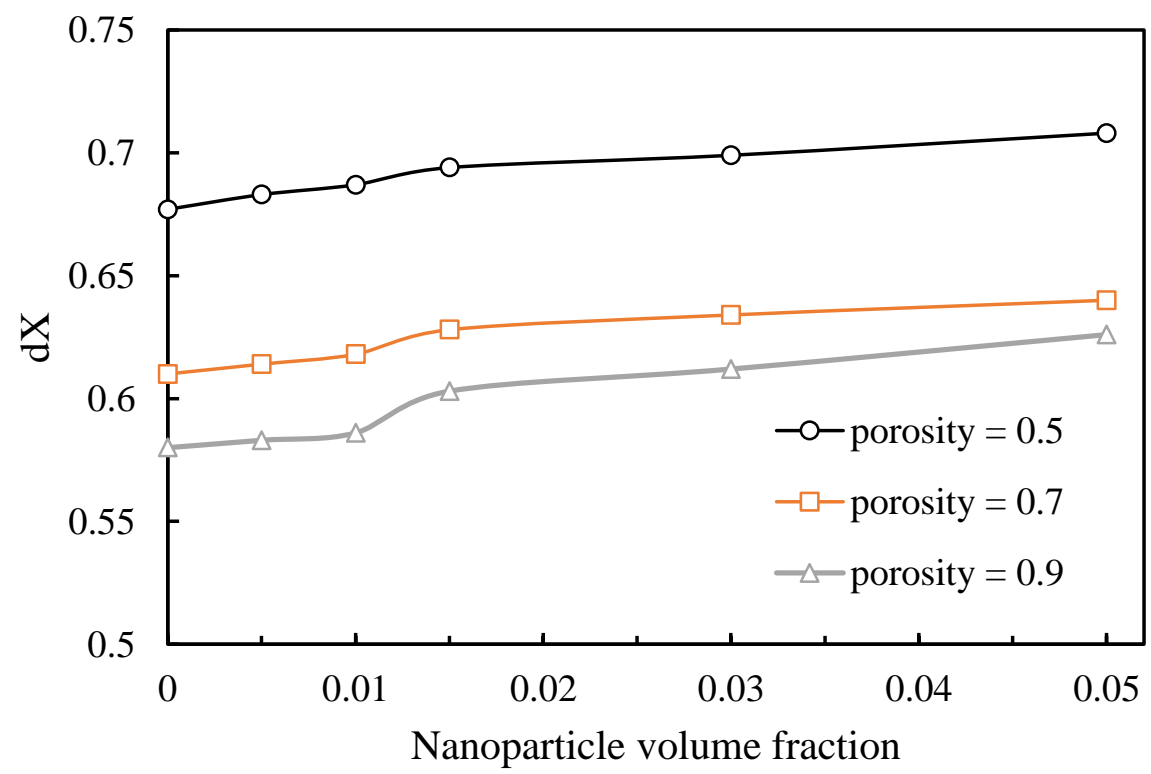

Figure 12. The variation of vapour fraction in terms of nanoparticle volume fraction for different metal foam porosities. 


\subsection{Study of heat transfer coefficient}

Figure 13 shows the variation of heat transfer coefficient as a function of porosity for different heat fluxes on the walls for $\varphi=0.01, \omega=20$ and $V_{\text {in }}=0.05 \mathrm{~m} / \mathrm{s}$. Reducing the porosity of the metal foam results in a higher amount of high conductivity metal inside the porous medium and therefore the effective thermal conductivity of the foam enhances. It can also be obtained from Eq. (15). For a higher thermal conductivity, a higher rate of heat transfer is achieved from the pipe wall to the fluid results in a lower temperature difference between the fluid and the pipe's wall. It can be explained according to Fig. 10 showing the variation of vapour fraction in terms of porosity. As shown, a higher amount of vapour is produced for a lower porosity as a result of a higher rate of heat transfer. This behaviour agrees with the results found in Zheng et. al [78] and Z.G.Qu et. al [79]. Furthermore, for a higher wall heat flux, the heat transfer coefficient enhances. By increasing the heat flux applied on the walls, the fluid temperature enhances and therefore a higher temperature difference between the inlet and outlet of the pipe occurs. Based on Equation (21), the results show that the effect of increasing the heat flux is higher than the temperature difference in the domain.

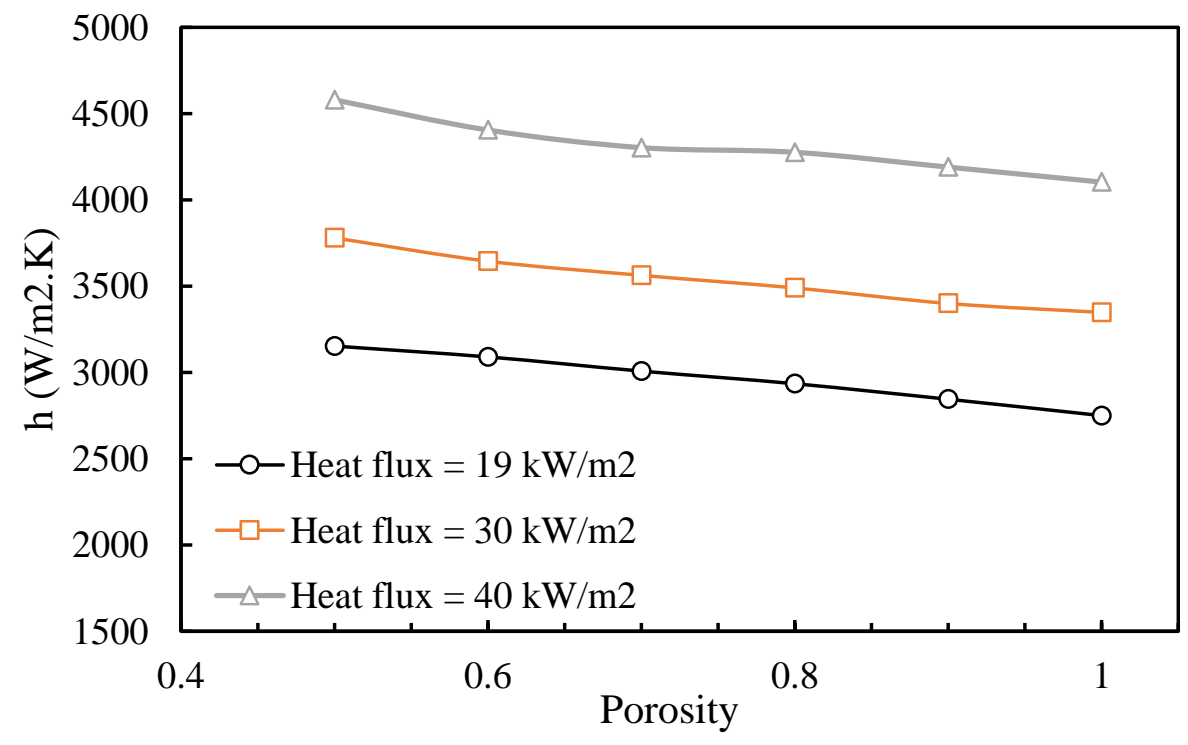

Figure 13. The variation of vapour fraction in terms of the porosity for different values of input heat fluxes.

Figure 14 illustrates the variation of heat transfer coefficient as a function of flow velocity for different pore density for $\varphi=0.01, \varepsilon=0.9$ and $\dot{Q_{w}}=19 \mathrm{~kW} / \mathrm{m}^{2}$. The heat transfer increases for a higher inlet velocity of the fluid flow due to higher convection heat transfer by increasing the fluid velocity [80]. It can also be explained according to the decreasing of vapour fraction by increasing the inlet velocity as mentioned in the previous section. Moreover, for a constant wall heat flux, increasing the inlet velocity results in a lower outlet temperature of the 
fluid flow and therefore, based on Equation (21), a higher heat transfer coefficient is achieved. Furthermore, for a higher pore density, the heat transfer coefficient increases due to a higher rate of heat transfer in the domain, which causes by the increase in the surface area, this also, confirmed by Z.G. Qu et. al [79].

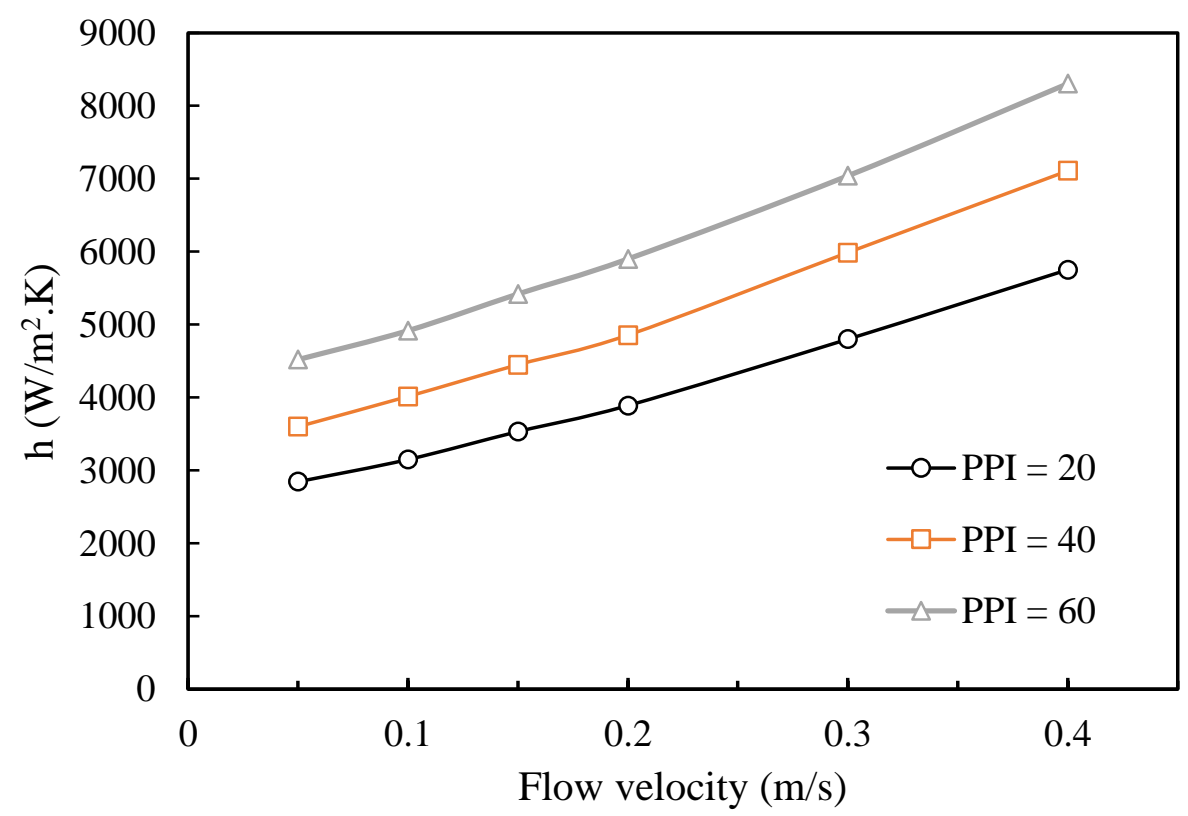

Figure 14. The variation of heat transfer coefficient in terms of the flow velocity for different values of pore density of the metal foam.

Figure 15 shows the variation of heat transfer coefficient as a function of volume fraction of nanoparticles for different porosity of the metal foam for $\dot{Q}_{w}=19 \mathrm{~kW} / \mathrm{m}^{2}, \omega=20$ and $V_{\text {in }}=$ $0.05 \mathrm{~m} / \mathrm{s}$. By increasing the concentration of nanoparticles, the heat transfer coefficient enhances, because of the high thermal conductivity of the nanoparticles which increase the thermal of then nanofluid on one hand and carry heat from the surface away to the fluid which help to increase the heat transfer rate on the other hand. 


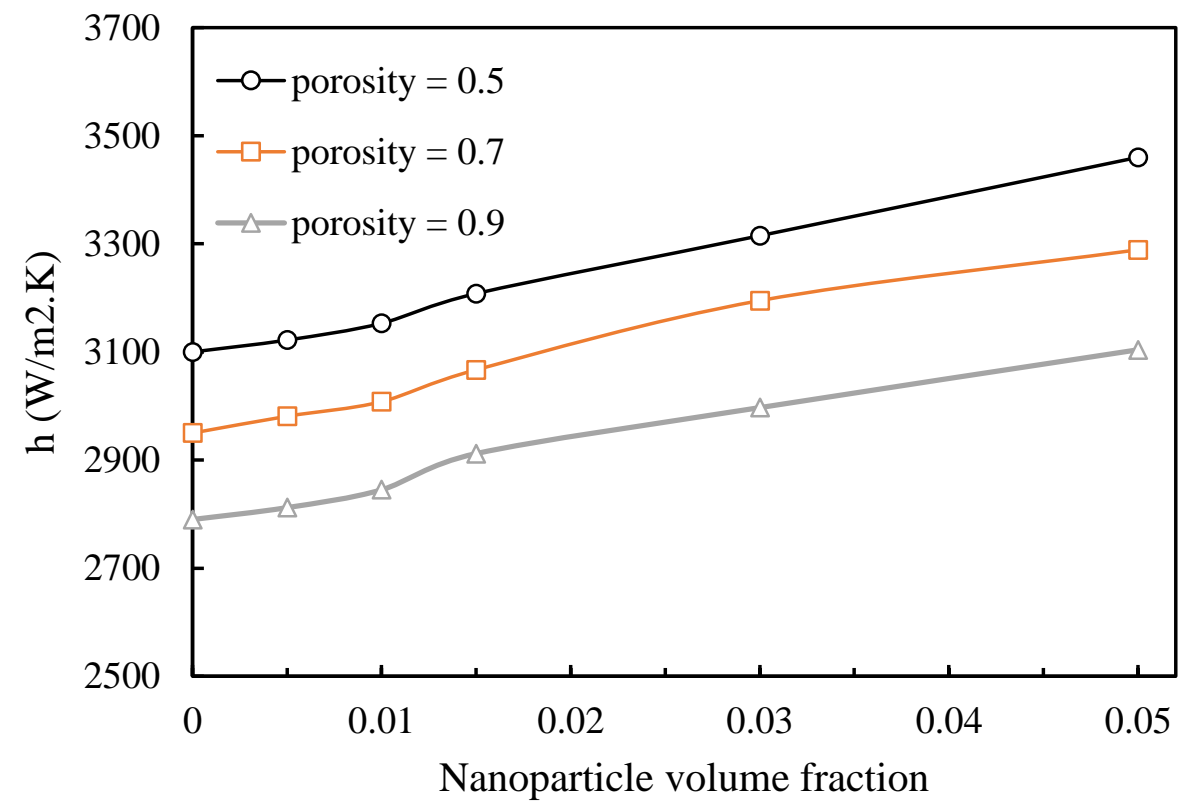

Figure 15. The variation of heat transfer coefficient in terms of nanoparticle volume fraction for different metal foam porosities.

\subsection{Summary of the results}

Table 3 represents the percentage of variation in different parameters including the pressure drop per unit length, vapour quality and overall heat transfer coefficient in terms of metal foam porosity for $\varphi=0.01, \omega=20 P P I, V_{i n}=0.05 \mathrm{~m} / \mathrm{s}$ and $\dot{Q_{w}}=19 \mathrm{~kW} / \mathrm{m}^{2}$. For a very low porosity $(<70 \%)$, the pressure drop is too high. On the other hand, for a high porosity such as $90 \%$, the effect of metal foam addition does not much increase the vapour volume production and overall heat transfer coefficient. Therefore, a system with a moderate porosity is recommended in this study.

Table 3 The effect of porosity on pressure drop per unit length, vapour quality and overall heat transfer coefficient

\begin{tabular}{llll}
\hline Porosity & $\mathrm{dp} / \mathrm{L}(\mathrm{kPa} / \mathrm{m})$ & $\mathrm{dX}$ & $\mathrm{h}\left(\mathrm{W} / \mathrm{m}^{2} \mathrm{~K}\right)$ \\
\hline 0.5 & 115.65 & 0.687 & 3153 \\
0.6 & 95.3 & 0.658 & 3090 \\
0.7 & 86.5 & 0.618 & 3008 \\
0.8 & 77.2 & 0.598 & 2935 \\
0.9 & 70 & 0.586 & 2845 \\
\hline
\end{tabular}

Table 4 represents the percentage of variation due to different parameters of pressure drop per unit length, vapour quality and overall heat transfer coefficient in terms of metal foam pore density for $\varphi=0.01, \varepsilon=90 \%, V_{i n}=0.05 \mathrm{~m} / \mathrm{s}$ and $\dot{Q_{w}}=19 \mathrm{~kW} / \mathrm{m}^{2}$. All the parameters of pressure drop per unit length, vapour quality and overall heat transfer coefficient increase with 
increasing the pore density of the metal foam. Therefore, a system with a small pore size (high pore density) is recommended which depends on the allowed pressure drop.

Table 4 The effect of pore density on pressure drop per unit length, vapour quality and overall heat transfer coefficient

\begin{tabular}{llll}
\hline Pore density & $\mathrm{dp} / \mathrm{L}(\mathrm{kPa} / \mathrm{m})$ & $\mathrm{dX}$ & $\mathrm{h}\left(\mathrm{W} / \mathrm{m}^{2} \mathrm{~K}\right)$ \\
\hline 20 & 70 & 0.586 & 2845 \\
40 & 83 & 0.635 & 3600 \\
60 & 102 & 0.676 & 4520 \\
\hline
\end{tabular}

The characteristics of the porous medium are determined based on the required vapour quality and the allowed pressure drop varied in different studies.

\section{Conclusion}

In this paper, the boiling heat transfer and two-phase flow modelling of nanofluid were studied in a horizontal tube filled with a high thermal conductivity copper foam. The aim of using a porous medium is to increase the rate of heat transfer and as a result higher vapour production of nanofluid; however, a higher pressure drop is achieved due to flow resistance by the metal foam. The effects of different parameters i.e. the porosity and pore density of the metal foam, inlet velocity, induced heat flux and volume fraction of nanoparticles on the pressure drop, vapour quality and overall heat transfer coefficient were studied. There is a significant advantage of the presence of a metal foam on the vapour production of nanofluid during the boiling process. By decreasing the porosity and increasing the pore density of the metal foam, higher volume fraction of vapour and pressure drop are achieved in the pipe outlet and its effectiveness is determined based on the nanofluid velocity and induced heat flux applied on the walls. For example, for the heat flux of $19 \mathrm{~kW} / \mathrm{m}^{2}$ and inlet velocity of $0.05 \mathrm{~m} / \mathrm{s}$, by using a metal foam with the porosity of $70 \%$ and pore density of $20 \mathrm{PPI}$, the vapour quality, heat transfer coefficient and pressure drop enhances by $7.1 \%, 9.4 \%$ and $82.7 \%$, respectively, compared with the case of without metal foam. Therefore, a system with a moderate porosity and a high pore density is recommended which is finally determined based on the required vapour production and allowed pressure drop.

\section{Acknowledgement}

This work was funded by The Higher Committee for Education Development (HCED), Iraq, by sponsorship reference D-12-1257 through the PhD Fellowship of the first author. 


\section{References}

[1] Hsieh W.H., Wu J.Y., Shih W.H., Chiu W.C., Experimental investigation of heat-transfer characteristics of aluminum-foam heat sinks, International Journal of Heat and Mass Transfer, 47 (2004) 5149-5157.

[2] Choon N.K., Chakraborty A., Aye S.M., Xiaolin W., New pool boiling data for water with copper-foam metal at sub-atmospheric pressures: Experiments and correlation, Applied Thermal Engineering, 26 (2006) 1286-1290.

[3] Lu W., Zhao C.Y., Xu Z.Y., Tassou S., The R134a Vapour Flow Heat Transfer in Horizontal Metal-Foam Tubes, in: 10th UK National Heat Transfer Conference, Edinburg, UK, 2007.

[4] Zhao C.Y., Lu W., Tassou S.A., Flow Boiling Heat Transfer in Horizontal Metal-Foam Tubes, Journal of Heat Transfer, 131 (2009) 121002-121002-121008.

[5] Sertkaya A.A., Altınısık K., Dincer K., Experimental investigation of thermal performance of aluminum finned heat exchangers and open-cell aluminum foam heat exchangers, Experimental Thermal and Fluid Science, 36 (2012) 86-92.

[6] Irwansyah R., Putra N., Pool Boiling of Nanofluids in Vertical Porous Media, Applied Mechanics and Materials, 388 (2013) 18-22.

[7] Xiao Z., Zhao Y., Heat transfer coefficient of porous copper with homogeneous and hybrid structures in active cooling, Journal of Materials Research, 28 (2013) 2545-2553.

[8] Amani M., Ameri M., Kasaeian A., The Experimental Study of Convection Heat Transfer Characteristics and Pressure Drop of Magnetite Nanofluid in a Porous Metal Foam Tube, Transport in Porous Media, 116 (2017) 959-974.

[9] Liao Q., Zhao T.S., A visual study of phase-change heat transfer in a two-dimensional porous structure with a partial heating boundary, International Journal of Heat and Mass Transfer, 43 (2000) 1089-1102.

[10] Raffray A.R., Pulsifer J.E., MERLOT: a model for flow and heat transfer through porous media for high heat flux applications, Fusion Engineering and Design, 65 (2003) 57-76.

[11] Imke U., Porous media simplified simulation of single- and two-phase flow heat transfer in micro-channel heat exchangers, Chemical Engineering Journal, 101 (2004) 295-302.

[12] Zhao C.Y., Lu W., Tassou S.A., Thermal analysis on metal-foam filled heat exchangers. Part II: Tube heat exchangers, International Journal of Heat and Mass Transfer, 49 (2006) 2762-2770.

[13] Lu W., Zhao C.Y., Tassou S.A., Thermal analysis on metal-foam filled heat exchangers. Part I: Metal-foam filled pipes, International Journal of Heat and Mass Transfer, 49 (2006) 2751-2761.

[14] Milani Shirvan K., Ellahi R., Mirzakhanlari S., Mamourian M., Enhancement of heat transfer and heat exchanger effectiveness in a double pipe heat exchanger filled with porous media: Numerical simulation and sensitivity analysis of turbulent fluid flow, Applied Thermal Engineering, 109 (2016) 761-774.

[15] Nazari S., Toghraie D., Numerical simulation of heat transfer and fluid flow of Water$\mathrm{CuO}$ Nanofluid in a sinusoidal channel with a porous medium, Physica E: Low-dimensional Systems and Nanostructures, 87 (2017) 134-140.

[16] Yeo D.Y., No H.C., Modeling film boiling within chimney-structured porous media and heat pipes, International Journal of Heat and Mass Transfer, 124 (2018) 576-585.

[17] Qu Z.G., Li W.Q., Tao W.Q., Numerical model of the passive thermal management system for high-power lithium ion battery by using porous metal foam saturated with phase change material, International Journal of Hydrogen Energy, 39 (2014) 3904-3913.

[18] Liu Z., Yao Y., Wu H., Numerical modeling for solid-liquid phase change phenomena in porous media: Shell-and-tube type latent heat thermal energy storage, Applied Energy, 112 (2013) 1222-1232. 
[19] Li W.Q., Qu Z.G., He Y.L., Tao Y.B., Experimental study of a passive thermal management system for high-powered lithium ion batteries using porous metal foam saturated with phase change materials, Journal of Power Sources, 255 (2014) 9-15. [20] Ren Q., He Y.-L., Su K.-Z., Chan C.L., Investigation of the effect of metal foam characteristics on the PCM melting performance in a latent heat thermal energy storage unit by pore-scale lattice Boltzmann modeling, Numerical Heat Transfer, Part A: Applications, 72 (2017) 745-764.

[21] Ren Q., Meng F., Guo P., A comparative study of PCM melting process in a heat pipeassisted LHTES unit enhanced with nanoparticles and metal foams by immersed boundarylattice Boltzmann method at pore-scale, International Journal of Heat and Mass Transfer, 121 (2018) 1214-1228.

[22] Talebizadeh Sardari P., Gidding D., Gillott M., Grant D., Walker G., Effect of Air channel Geometry on the Performance of a Composite Metal Foam-PCM to Air Heat Exchanger, in: Innovative Applied Energy (IAPE 2109), Oxford, United Kingdom, 14-15 March 2019.

[23] Han X.-H., Wang Q., Park Y.-G., T'joen C., Sommers A., Jacobi A., A review of metal foam and metal matrix composites for heat exchangers and heat sinks, Heat Transfer Engineering, 33 (2012) 991-1009.

[24] Hu H., Lai Z., Ding G., Influence of surface wettability on heat transfer and pressure drop characteristics of wet air in metal foam under dehumidifying conditions, International Journal of Thermal Sciences, 135 (2019) 331-343.

[25] Hu H., Lai Z., Ding G., Heat transfer and pressure drop characteristics of wet air flow in metal foam with hydrophobic coating under dehumidifying conditions, Applied Thermal Engineering, 132 (2018) 651-664.

[26] Hu H., Weng X., Zhuang D., Ding G., Lai Z., Xu X., Heat transfer and pressure drop characteristics of wet air flow in metal foam under dehumidifying conditions, Applied Thermal Engineering, 93 (2016) 1124-1134.

[27] Hu H., Lai Z., Ding G., Zhuang D., Weng X., Experimental investigation on water drainage characteristics of open-cell metal foams with different wettabilities, international journal of refrigeration, 79 (2017) 101-113.

[28] Hu H., Zhu Y., Peng H., Ding G., Sun S., Influence of tube diameter on heat transfer characteristics of refrigerant-oil mixture flow boiling in metal-foam filled tubes, International Journal of Refrigeration, 41 (2014) 121-136.

[29] Zhu Y., Hu H., Ding G., Peng H., Huang X., Zhuang D., Yu J., Influence of oil on nucleate pool boiling heat transfer of refrigerant on metal foam covers, international journal of refrigeration, 34 (2011) 509-517.

[30] Li H.-W., Zhang C.-Z., Yang D., Sun B., Hong W.-P., Experimental investigation on flow boiling heat transfer characteristics of R141b refrigerant in parallel small channels filled with metal foam, International Journal of Heat and Mass Transfer, 133 (2019) 21-35.

[31] Talebizadeh Sardari P., Walker G.S., Gillott M., Grant D., Giddings D., Numerical modelling of phase change material melting process embedded in porous media: Effect of heat storage size, Proceedings of the Institution of Mechanical Engineers, Part A: Journal of Power and Energy, (2019) 0957650919862974.

[32] Chen Z.Q., Cheng P., Zhao T.S., An experimental study of two phase flow and boiling heat transfer in bi-dispersed porous channels, International Communications in Heat and Mass Transfer, 27 (2000) 293-302.

[33] Gourbil A., Duru P., Fichot F., Quintard M., Prat M., Experimental study of boiling in porous media: effect of the void fraction on the critical heat flux, in: 9th International Symposium on Heat Transfer ISHT-9, oatao:16112, 2016, pp. 1-7. 
[34] Hu H., Zhu Y., Peng H., Ding G., Sun S., Effect of tube diameter on pressure drop characteristics of refrigerant-oil mixture flow boiling inside metal-foam filled tubes, Applied Thermal Engineering, 62 (2014) 433-443.

[35] Weise S., Meinicke S., Wetzel T., Dietrich B., Modelling the pressure drop of two-phase flow through solid porous media, International Journal of Multiphase Flow, 112 (2019) 1326.

[36] Ramesh P.S., Torrance K.E., Boiling in a porous layer heated from below: effects of natural convection and a moving liquid/two-phase interface, Journal of Fluid Mechanics, 257 (1993) 289-309.

[37] Zhang S., Sun Y., Yuan W., Tang Y., Tang H., Tang K., Effects of heat flux, mass flux and channel width on flow boiling performance of porous interconnected microchannel nets, Experimental Thermal and Fluid Science, 90 (2018) 310-318.

[38] Samir A., Hussain I.Y., Simulation of natural convection boiling heat transfer for refrigerant R-134a flow in a metal foam filled vertical tube, Case Studies in Thermal Engineering, 13 (2019) 100390.

[39] Tarawneh M., Performance study on the evaporation and pressure drop of lowtemperature refrigerant blends in porous media, Heat Transfer Asian Research, 48 (2019) $1381-1398$.

[40] Fang X., Chen Y., Zhang H., Chen W., Dong A., Wang R., Heat transfer and critical heat flux of nanofluid boiling: A comprehensive review, Renewable and Sustainable Energy Reviews, 62 (2016) 924-940.

[41] Das S.K., Putra N., Roetzel W., Pool boiling of nano-fluids on horizontal narrow tubes, International Journal of Multiphase Flow, 29 (2003) 1237-1247.

[42] Vassallo P., Kumar R., D’Amico S., Pool boiling heat transfer experiments in silicawater nano-fluids, International Journal of Heat and Mass Transfer, 47 (2004) 407-411.

[43] Bang I.C., Chang S.H., Boiling heat transfer performance and phenomena of Al 2 O 3water nano-fluids from a plain surface in a pool, International Journal of Heat and Mass Transfer, 48 (2005) 2407-2419.

[44] Kim H., Kim J., Kim M.H., Effect of nanoparticles on CHF enhancement in pool boiling of nano-fluids, International Journal of Heat and Mass Transfer, 49 (2006) 5070-5074.

[45] Coursey J.S., Kim J., Nanofluid boiling: The effect of surface wettability, International Journal of Heat and Fluid Flow, 29 (2008) 1577-1585.

[46] Trisaksri V., Wongwises S., Nucleate pool boiling heat transfer of TiO2-R141b nanofluids, International Journal of Heat and Mass Transfer, 52 (2009) 1582-1588.

[47] Soltani S., Etemad S.G., Thibault J., Pool boiling heat transfer of non-Newtonian nanofluids, International Communications in Heat and Mass Transfer, 37 (2010) 29-33. [48] Kim H., Ahn H.S., Kim M.H., On the Mechanism of Pool Boiling Critical Heat Flux Enhancement in Nanofluids, Journal of Heat Transfer, 132 (2010) 061501-061501-061511.

[49] Dadjoo M., Etesami N., Esfahany M.N., Influence of orientation and roughness of heater surface on critical heat flux and pool boiling heat transfer coefficient of nanofluid, Applied Thermal Engineering, 124 (2017) 353-361.

[50] Gobinath N., Venugopal T., Palani K., Samuel A.A., Numerical modelling of thermophoresis in water-alumina nanofluid under pool boiling conditions, International Journal of Thermal Sciences, 129 (2018) 1-13.

[51] Geng Y., Al-Rashed A.A., Mahmoudi B., Alsagri A.S., Shahsavar A.,

Talebizadehsardari P., Characterization of the nanoparticles, the stability analysis and the evaluation of a new hybrid nano-oil thermal conductivity, Journal of Thermal Analysis and Calorimetry, (2019) 1-12.

[52] Peng H., Ding G., Jiang W., Hu H., Gao Y., Heat transfer characteristics of refrigerantbased nanofluid flow boiling inside a horizontal smooth tube, International Journal of Refrigeration, 32 (2009) 1259-1270. 
[53] Henderson K., Park Y.-G., Liu L., Jacobi A.M., Flow-boiling heat transfer of R-134abased nanofluids in a horizontal tube, International Journal of Heat and Mass Transfer, 53 (2010) 944-951.

[54] Kim T.I., Jeong Y.H., Chang S.H., An experimental study on CHF enhancement in flow boiling using Al2O3 nano-fluid, International Journal of Heat and Mass Transfer, 53 (2010) 1015-1022.

[55] Sun B., Yang D., Flow boiling heat transfer characteristics of nano-refrigerants in a horizontal tube, International Journal of Refrigeration, 38 (2014) 206-214.

[56] Rana K.B., Agrawal G.D., Mathur J., Puli U., Measurement of void fraction in flow boiling of $\mathrm{ZnO}-$ water nanofluids using image processing technique, Nuclear Engineering and Design, 270 (2014) 217-226.

[57] Nikkhah V., Sarafraz M.M., Hormozi F., Application of Spherical Copper Oxide (II) Water Nano-fluid as a Potential Coolant in a Boiling Annular Heat Exchanger, Chemical and biochemical engineering quarterly, , 29(3) (2015) 11.

[58] Patra N., Gupta V., Pradyumna E., Singh R., Ghosh P., Singh R.S., Nayak A., Delay in DNB for flow boiling of diluted oxide based nanofluids, Experimental Thermal and Fluid Science, 89 (2017) 211-218.

[59] Zhou J., Luo X., Feng Z., Xiao J., Zhang J., Guo F., Li H., Saturated flow boiling heat transfer investigation for nanofluid in minichannel, Experimental Thermal and Fluid Science, 85 (2017) 189-200.

[60] Mohammed H.I., Giddings D., Walker G.S., CFD simulation of a concentrated salt nanofluid flow boiling in a rectangular tube, International Journal of Heat and Mass Transfer, 125 (2018) 218-228.

[61] Mohammed H.I., Giddings D., Walker G.S., Experimental investigation of nanoparticles concentration, boiler temperature and flow rate on flow boiling of zinc bromide and acetone solution in a rectangular duct, International Journal of Heat and Mass Transfer, 130 (2019) 710-721.

[62] Shahsavar A., Talebizadeh Sardari P., Toghraie D., Free convection heat transfer and entropy generation analysis of water-Fe3O4/CNT hybrid nanofluid in a concentric annulus, International Journal of Numerical Methods for Heat \& Fluid Flow, 29 (2019) 915-934.

[63] Shahsavar A., Godini A., Sardari P.T., Toghraie D., Salehipour H., Impact of variable fluid properties on forced convection of $\mathrm{Fe} 3 \mathrm{O}$ 4/CNT/water hybrid nanofluid in a doublepipe mini-channel heat exchanger, Journal of Thermal Analysis and Calorimetry, (2019) 113.

[64] Kim S.J., McKrell T., Buongiorno J., Hu L.-w., Subcooled flow boiling heat transfer of dilute alumina, zinc oxide, and diamond nanofluids at atmospheric pressure, Nuclear Engineering and Design, 240 (2010) 1186-1194.

[65] Afrand M., Abedini E., Teimouri H., Experimental investigation and simulation of flow boiling of nanofluids in different flow directions, Physica E: Low-dimensional Systems and Nanostructures, 87 (2017) 248-253.

[66] Py X., Olives R., Mauran S., Paraffin/porous-graphite-matrix composite as a high and constant power thermal storage material, International Journal of Heat and Mass Transfer, 44 (2001) 2727-2737.

[67] Nield D.A., Bejan A., Convection in Porous Media, Springer International Publishing, 2017.

[68] Akbari M., Galanis N., Behzadmehr A., Comparative analysis of single and two-phase models for CFD studies of nanofluid heat transfer, International Journal of Thermal Sciences, 50 (2011) 1343-1354.

[69] Delavari V., Hashemabadi S.H., CFD simulation of heat transfer enhancement of Al2O3/water and Al2O3/ethylene glycol nanofluids in a car radiator, Applied Thermal Engineering, 73 (2014) 380-390. 
[70] Mahdi J.M., Nsofor E.C., Melting enhancement in triplex-tube latent heat energy storage system using nanoparticles-metal foam combination, Applied Energy, 191 (2017) 22-34.

[71] Guide A.F.U.s., Version 15, ANSYS Inc., January, (2013).

[72] LEE W.H., A Pressure Iteration Scheme for Two-Phase Flow Modeling in T. N.

Veziroglu (ed.), Multiphase Transport Fundamentals, Reactor Safety, Applications, (1980).

[73] Gao L., Zhang L., Ma Z., Xu C., Xiao Z., Du M., The Numerical Simulation of Flow and Boiling Heat Transfer of Two Phases in Horizontal Tube, in: 2012 Asia-Pacific Power and Energy Engineering Conference, 2012, pp. 1-4.

[74] De Schepper S.C., Heynderickx G.J., Marin G.B., Modeling the evaporation of a hydrocarbon feedstock in the convection section of a steam cracker, Computers \& Chemical Engineering, 33 (2009) 122-132.

[75] Masoumi N., Sohrabi N., Behzadmehr A., A new model for calculating the effective viscosity of nanofluids, Journal of Physics D: Applied Physics, 42 (2009) 055501.

[76] Shahsavar A., Al-Rashed A.A., Entezari S., Sardari P.T., Melting and Solidification Characteristics of a Double-Pipe Latent Heat Storage System with Sinusoidal Wavy Channels Embedded in a Porous Medium, Energy, 171 (2019) 751-769.

[77] Zhao C., Lu W., Tassou S., Flow boiling heat transfer in horizontal metal-foam tubes, Journal of Heat Transfer, 131 (2009) 121002.

[78] Zheng B., Liu Y., Zou L., Li R., Heat Transfer Characteristics of Calcined Petroleum Coke in Waste Heat Recovery Process, Mathematical Problems in Engineering, 2016 (2016) 9.

[79] Z.G. Qu, H.J. Xu, T.S. Wang, W.Q. Tao, Lu T.J., Thermal Transport in Metallic Porous Media, 2011.

[80] Bejan A., Convection heat transfer, John wiley \& sons, 2013. 